\title{
Independent Seismic Evaluation of the 24-580-980 South Connector Ramps
}

\author{
Synthetic Strong Ground Motions for a \\ Magnitude 7.25 Hayward Fault Earthquake
}

\author{
Lawrence J. Hutchings \\ Paul W. Kasameyer \\ Stephen P. Jarpe \\ William Foxall
}

May 1997

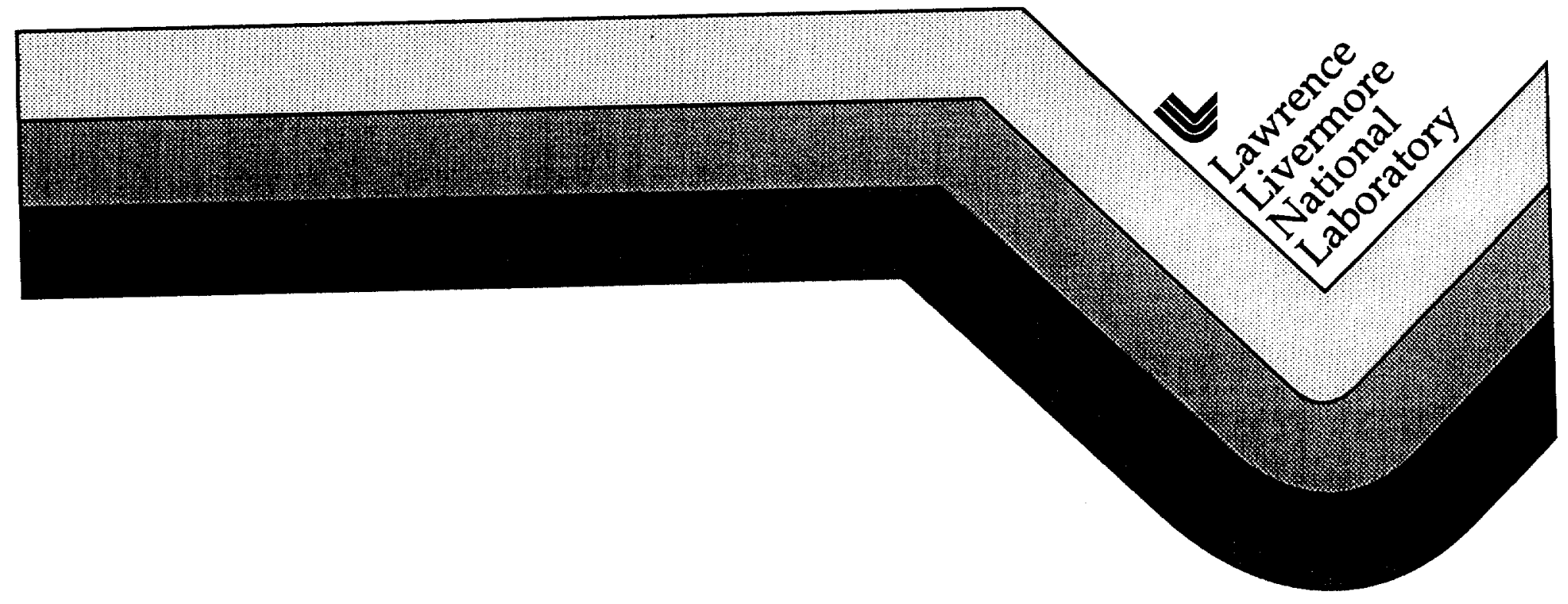




\section{DISCLAIMER}

This document was prepared as an account of work sponsored by an agency of the United States Government. Neither the United States Government nor the University of California nor any of their employees, makes any warranty, express or implied, or assumes any legal liability or responsibility for the accuracy, completeness, or usefulness of any information, apparatus, product, or process disclosed, or represents that its use would not infringe privately owned rights. Reference herein to any specific commercial product, process, or service by trade name, trademark, manufacturer, or otherwise, does not necessarily constitute or imply its endorsement, recommendation, or favoring by the United States Government or the University of Californin. The views and opinions of authors expressed herein do not necessarily state or reflect those of the United States Government or the University of California, and shall not be used for advertising or product endorsement purposes.

Work performed under the auspices of the U.S. Department of Energy by Lawrenoe Livermore National Laboratory under Contract W-7405-ENG-48. 
UCRL-ID-123201

Volume 1

\title{
Independent Seismic Evaluation of the 24-580-980 South Connector Ramps
}

\section{Synthetic Strong Ground Motions for a Magnitude 7.25 Hayward Fault Earthquake}

\author{
Lawrence J. Hutchings, Paul W. Kasameyer, \\ Stephen P. Jarpe, and William Foxall \\ Prepared for \\ California Department of Transportation \\ Division of Structures \\ Lawrence Livermore National Laboratory \\ P.O. Box 808 \\ Livermore, California 94551
}

May 9, 1997 


\section{Contents}

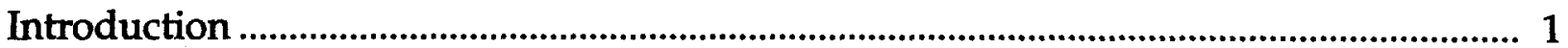

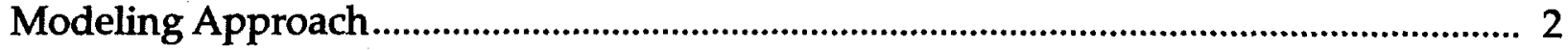

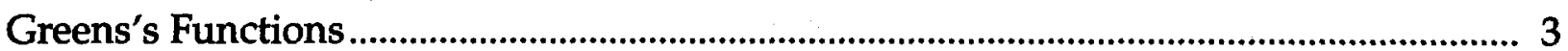

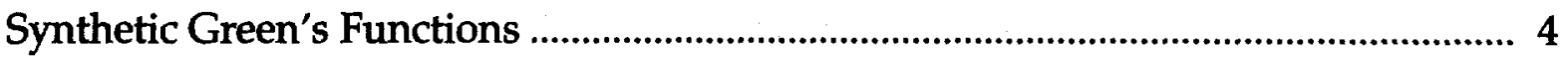

Empirical Green's Functions........................................................................... 5

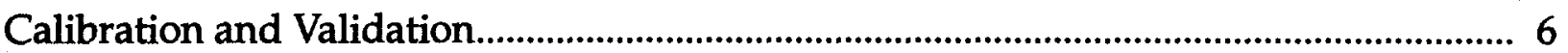

Near-Source Strong Ground Motion ......................................................................... 8

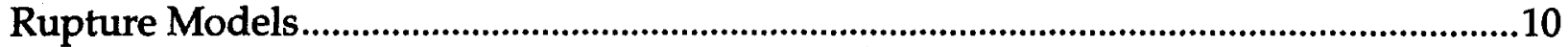

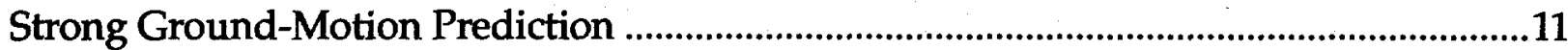

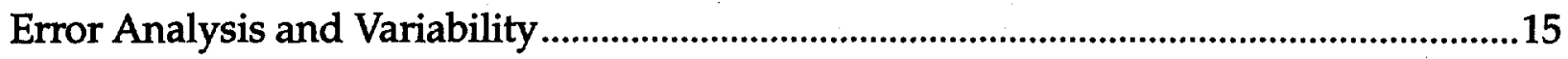

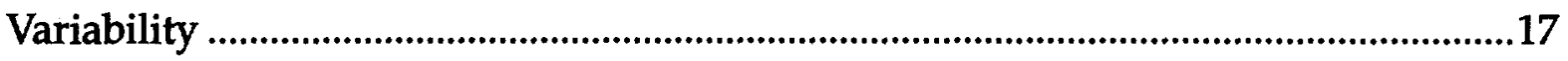

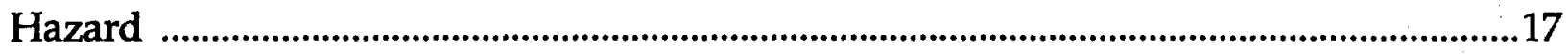

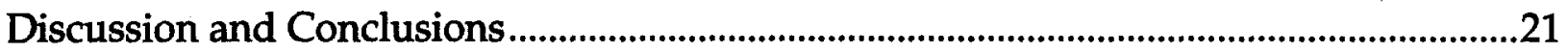

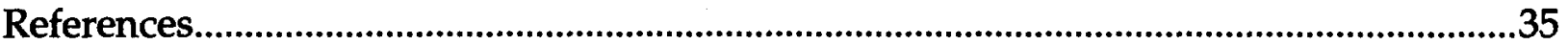




\section{List of Figures}

Fig. 1 Faults in the San Francisco Bay area. For this study, the areaof the Hayward fault between the two crosses is assumed to rupture. Asterisks indicate source locations of small earthquakes recorded at BKS, and the octagons indicate events recorded at YBI........................................ 1

Fig. 2 Velocity model and the linearized approximation used in this study ................. 5

Fig. 3 Synthetic ground motion for the fault parallel (N145E) components of ground velocity at locations on the fault.

Fig. 4 Synthetic ground motion for the fault-normal (N235E) components of ground velocity at locations at the Stack ( $4.3 \mathrm{~km}$ distant).

Fig. 5 The location of all asperities and hypocenters for the one hundred models

Fig. 6 Displacement contour plots of various scenarios. The slip distribution varies considerably between the different scenarios

Fig. 7 The absolute acceleration response spectra (average for two horizontals) computed from accelerograms from the one hundred scenarios

Fig. 8 The distribution of the natural log of the calculated AARS value at a period of $0.5 \mathrm{sec}$.

Fig. 9 The log-normal mean (arithmetic median), and \pm 1 standard deviation absolute acceleration response spectra values (16 and $84 \%$ confidence limits) from the one hundred scenarios

Fig. 10 Changes in the mean and one standard deviation values as the number of scenarios increased

Fig. 11 The \pm 1 standard deviation estimates for the mean and (mean +1 standard deviation) values as a function of $n$

Fig. 12 The same values as Figure 11, but with the assumption that the uncertainties in the mean and standard deviation added in quadrature.

Fig. 13 The median (log-normal mean), \pm 1 standard deviation response spectra from the 100 rupture scenarios. Model HAY31 generated time histories that most closely match the +1 standard deviation value

Fig.14 The slip distribution and hypocenter of scenario HAY31. There is one small asperity at the hypocenter for this model

Fig. 15 Time histories for frequencies 0.05 to $33.0 \mathrm{~Hz}$; the top three are the three components of acceleration, the middle three are the same records integrated to displacement, and the bottom three are the displacement values.

Fig.16 The displacement contours and hypocenter for model HAY06. There are two asperities for this model, one at the hypocenter and one between 70 and $80 \mathrm{~km}$ near the bottom of the fault 
Fig. 17 Time histories; the top three are the three components of acceleration, the middle three are the same records integrated to displacement, and the bottom three are the displacement values

Fig. 18 Peak acceleration and peak velocity values from the $M=6.9$, 1995 Kobe earthquake, along with values for scenarios HAY31 and HAY06 for the $M=7.25$ Hayward fault earthquake. Figure modified from Somerville (1995, Figure 10) 26

Fig. 19 The location of two sites that recorded high acceleration response values ........27

Fig. 20 The results from scenarios HAY31 ......................................................................28

Fig. 21 The results from scenarios HAY31 …………….....................................................28 


\section{List of Tables}

Table 1 List of the rupture parameters used in this study

Table 2 Strong motion recordings less than $5 \mathrm{~km}$ from $M \geq 6.9$ earthquakes.

Data from Somerville (1995).

Table 3 Fault normal (FN) and fault parallel (FP) values of peak acceleration and velocity. Data from Somerville (1995) 


\section{Introduction}

The interchange for highways 24,580, and 980 (the Stack) in Oakland, California, lies $4.3 \mathrm{~km}$ from the surface expression of the Hayward fault and $26 \mathrm{~km}$ from the San Andreas fault. The purpose of this project is to compute realistic, linear, strong ground motion (rock outcrop motion) likely to affect this interchange during a hazardous earthquake on the Hayward fault. With the exception of very long period ( $220 \mathrm{sec})$ motion, the Hayward fault will be the controlling deterministic ground motion hazard to this structure. Figure 1 shows the locations of the Stack and the Hayward fault. We identified a magnitude $M=7.25$ earthquake that ruptures $82 \mathrm{~km}$ of the Hayward fault as the principal hazard to the Stack; it has a moment of $8.5 \times 10^{26}$ dyne-cm. Moment magnitudes (Hanks and Kanamori, 1979) are used in this report. Our goal is to produce realistic synthesized ground motion for three components and the full wavetrain and for frequencies from 0.05 to $33.0 \mathrm{~Hz}$.

A realistic synthesis of ground motion should include the effects of geologic conditions along the propagation path from the fault and at the site itself. Geologic conditions can significantly alter the amplitudes of seismic energy, and can cause focusing and scattering of energy. To control these factors, we used empirical Green's functions to synthesize frequencies from 0.5 to $25.0 \mathrm{~Hz}$, and synthetic Green's functions for frequencies

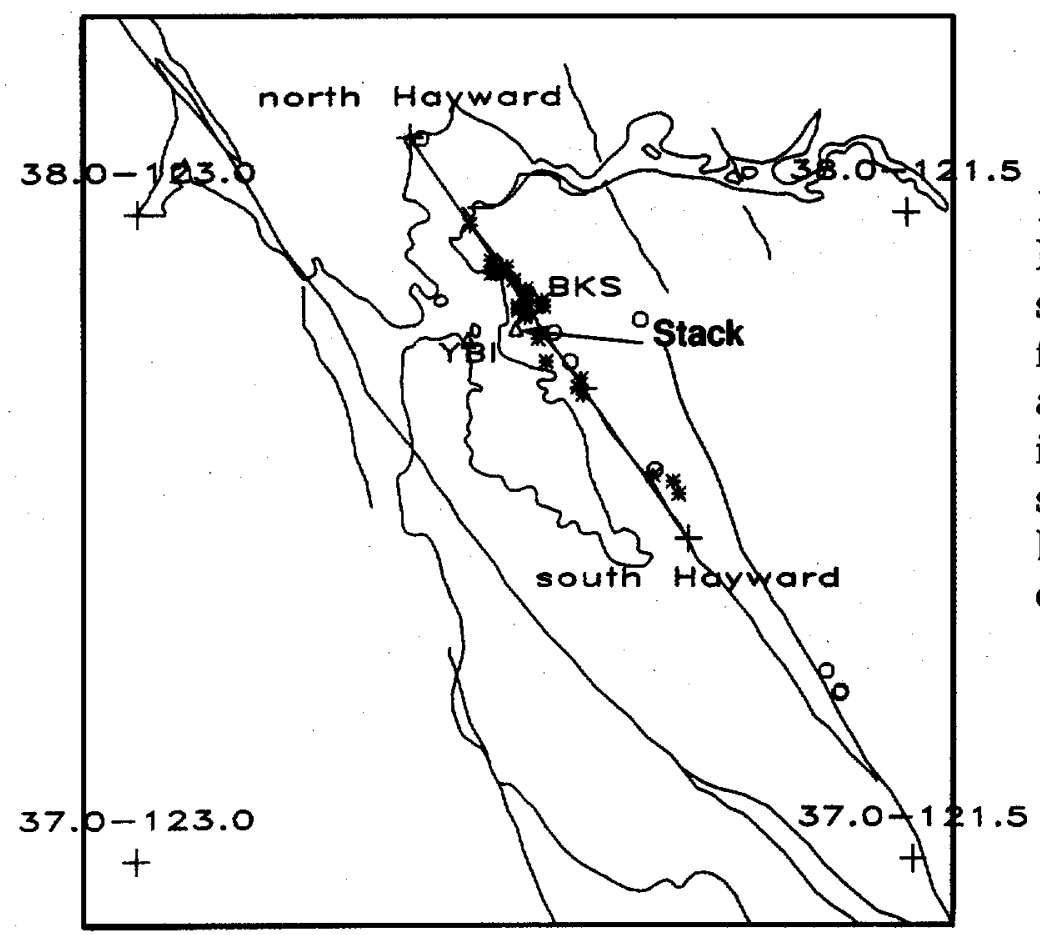

Figure 1. Faults in the San Francisco Bay area. For this study, the area of the Hayward fault between the two crosses is assumed to rupture. Asterisks indicate source locations of small earthquakes recorded at $\mathrm{BKS}$, and the octagons indicate events recorded at YBI. 
0.05 to $0.5 \mathrm{~Hz}$. The empirical Green's functions were recorded at two rock outcrop sites ( $3.8 \mathrm{~km}$ north and $12.8 \mathrm{~km}$ west) near the Stack, and were then interpolated to represent recordings at the interchange. Therefore, the results of this study cannot be viewed as specific to the Stack location, but rather as those that might result from a typical rock outcrop site in the area of the Stack.

Due to the proximity of the Stack to the Hayward fault, it is critical to account for the effects of finite fault rupture. These include simultaneous seismic arrivals radiated from portions of the fault that can be tens of kilometers apart, and directivity effects that can significantly enhance amplitudes of the wave field. In addition, the superposition of body-waves and surface-waves result in an extremely complicated wave field and should be modeled. Site soil can also significantly affect ground motion, but here we only present ground motion that might be expected at a rock outcrop located at the Stack. Additional modeling of the soils will be necessary to account for the effect of soil layers.

We developed a suite of 100 rupture scenarios for an $M=7.25$ Hayward fault earthquake and computed the commensurate strong ground-motion time histories. Lognormal average and one standard deviation values of peak acceleration and absolute acceleration response spectra (AARS) were derived from the suite of synthesized strong ground motion. The scenarios were developed by randomly varying rupture parameters within a range of physical limits obtained from the work of others. The time histories used for input into the soils model are those whose absolute acceleration response spectra most closely match the median (log-normal mean) and the +1 standard deviation values. By having a suite of rupture scenarios of hazardous earthquakes for a fixed magnitude and identifying the hazard to the site from the one standard deviation value of engineering parameters, we have introduced a probabilistic component to the deterministic hazard calculation.

\section{Modeling Approach}

We model large earthquakes by solving the representation relation (Aki and Richards, 1980) for a finite earthquake rupture. In this solution, we discretize a potential fault rupture surface and appropriately sum point source Green's functions that are convolved with slip functions. This is the Green's function summation approach (Heaton, 1982). We have developed an exact solution to the representation relation that utilizes either empirical or synthetic Green's functions. Here, we use recordings of small earthquakes to provide empirical Green's functions for frequencies $0.5-33 \mathrm{~Hz}$, and analytical 
calculations to provide synthetic Green's functions for frequencies $0.05-0.5 \mathrm{~Hz}$. Empirical Green's functions are defined here as recordings of effectively impulsive point source events. Most empirical Green's function studies rely on scaling relations to determine the number of small earthquakes necessary to synthesize a large earthquake; these models have difficulty in matching the low and high frequency of synthesized seismograms to observed records (Joyner and Boore, 1986; Boatwright, 1988; Tumarkin et. al., 1994; Frankel, 1995). Our modeling approach only requires that the number of small earthquakes used in the synthesis is large enough so that the sum of their moments add up to the moment of the large earthquake, which matches the low frequency of observed seismograms. The high frequency is matched simply by using appropriate rupture parameters (Hutchings, 1994). Our modeling approach has been described in a series of publications: Hutchings and Wu, 1990; Hutchings, 1991; Hutchings, 1994; Jarpe and Kasameyer, 1995; Foxall et. al., 1996; Hutchings and Jarpe, 1995; and McCallen and Hutchings, 1995. The computer code EMPSYN is described in Hutchings (1988).

Our earthquake rupture models rely on moment, fault geometry, hypocenter, rupture roughness, rupture velocity, healing velocity, slip vector, and asperity location. Moment and fault geometry (extent of the rupture and its orientation) are held fixed, while the other parameters are allowed to vary within limits. The rupture initiates at the hypocenter and propagates radially at a percentage of the shear wave velocity. Slip at a point obtains the amplitude of the Kostrov slip function, but the shape is approximated as a ramp. We model the rupture process as a continuous rupture over the fault with variable slip amplitude that can result in multiple areas of high slip (for example, seven or less for a $M=7.25$ earthquake). These areas of high slip are called asperities in this report. Asperity size was arbitrarily chosen to add fairly large areas of higher slip as has been observed in studies of past earthquakes.

\section{Green's Functions}

The basic premise in synthesizing with empirical and synthetic Green's functions is that each offers the best accuracy over particular frequency bands. The empirical Green's functions are more accurate for high frequencies for which geologic inhomogeneities are not well modeled, and the synthetic Green's functions are more accurate for lower frequencies for which empirical Green's functions do not have sufficient energy. The overlap is in the range from 0.5 to $1.0 \mathrm{~Hz}$. In this range, the geology can be modeled 
with some accuracy, and the empirical Green's function have sufficient energy to be well recorded.

\section{Synthetic Green's Functions}

We computed synthetic Green's functions using the reflectivity code of Kennett (1983). The focal mechanism radiation pattern is used for synthetic Green's functions solutions to the finite rupture. This solution extends to zero frequency, but does not include near-field terms. We only considered solutions for frequencies greater than 0.05 $\mathrm{Hz}$ (20-sec period), because the lack of near-field arrivals diminish the reliability of solutions for frequencies lower than this.

To compute synthetic Green's functions, a velocity model is required. We combined studies of the velocity structure at different locations along the fault to form a composite velocity model for the entire segment. The crustal thickness was set to be consistent with Fuis and Mooney (1990). Velocity structures from studies of areas represented by five control points were combined to form the composite model for northern California. The velocity structure at five locations along the fault were interpreted from various studies. These individual velocity profiles were visually interpolated to determine the depths of interfaces between velocities at $0.5 \mathrm{~km} / \mathrm{sec}$ intervals, i.e., for each profile the depth of the interface between 5.5 and $6.0 \mathrm{~km} / \mathrm{sec}$ was found. Some velocities were not represented in most of the profiles, so were not included; the velocities used in the profile were $4.5,5.5,6.0,6.5$, and $8.0 \mathrm{~km} / \mathrm{sec}$. Once the depths of the interfaces were found for each control point, they were connected to form a linearly dependent velocity model with depth for the entire profile. Interface depths of the Hayward fault are 4.0, 7.0, 11.0 , and $23.0 \mathrm{~km}$.

The same velocity model is also used in EMPSYN to compute ray paths of synthetic and empirical Green's functions, to correct for differences in location and to correct focal mechanism solutions. The velocity model is also used by EMPSYN to compute rupture velocity as a percentage of shear wave velocity. The velocity model was linearized by the relation:

$$
V p=4.0+0.182 \mathrm{H},
$$

where $H$ is depth. This velocity model more closely approximates the layered velocity model at depth 0-13.0 km, where the primary rupture and empirical Green's functions occur. Figure 2 shows the velocity model obtained from the literature and the linearized approximation used in this report. 


\section{Empirical Green's Functions}

Empirical Green's functions should be recorded at the site of interest and from source events along the faults of interest, since site response and near-source propagation-path effects are highly variable. Empirical Green's functions include the actual effects of velocity structure, attenuation, and geometrical spreading. In this study, such recordings were not available since no recordings were made at the Stack site. The empirical Green's functions used are recordings of small earthquakes from the Berkeley broadband site (BKS, $3.8 \mathrm{~km}$ north, U. C., Berkeley Broadband Network, internet access) and from Yerba Buena Island (YBI, $12.6 \mathrm{~km}$ west, Jarpe et. al., 1989). BKS is closer to the site, and empirical Green's functions from YBI may better represent the geology at the Stack itself. However, BKS only records frequencies up to $5.0 \mathrm{~Hz}$, so BKS data were used only for frequencies $0.5-5.0 \mathrm{~Hz}$. Empirical Green's functions at YBI were used to represent frequencies from 5.0-33.0 Hz. Empirical Green's functions are extrapolated to have been recorded at the Stack. Hutchings and Wu (1990) found that interpolation for different site locations is not very reliable because site response changes considerably for shot separations along a fault. For example, Hutchings and Jarpe (1995) found that $600-\mathrm{m}$ spatial separations between sites situated on sandstone had considerably different site responses. However, Steidl et al., (1996) found that bedrock recordings at the bottom of bore holes were much more stable than surface rock recordings. Since the recordings at BKS are from the Berkeley Seismograph Station tunnel, it is hoped that they represent a more stable estimate

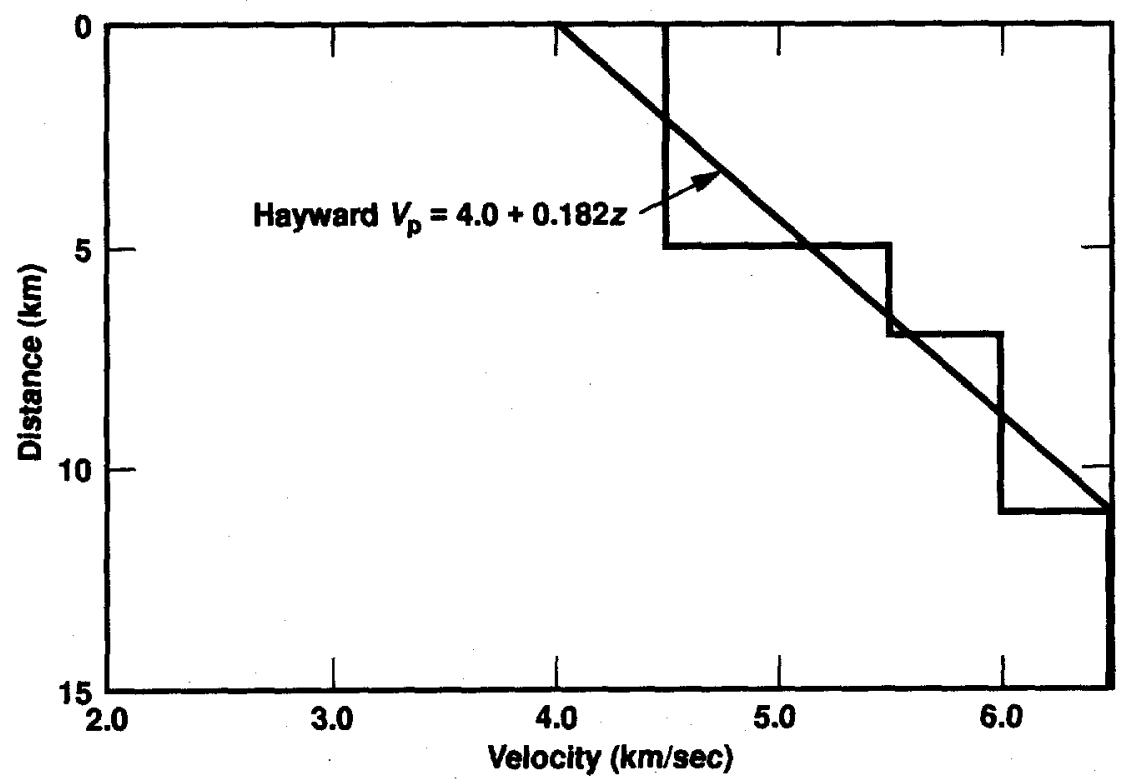

Figure 2. Velocity model and the linearized approximation used in this study. 
of local rock conditions. However, the results of this study cannot be viewed as specific to the Stack location, but rather those that might result from a typical rock outcrop site.

It is not possible to record empirical Green's functions from all locations along a fault of interest and with the same focal mechanism solution, so source locations of empirical Green's functions have been interpolated to fill in the fault. Figure 1 shows the epicenter locations of source events used for empirical Green's functions. The asterisks are the locations of events recorded at BKS, and the open octagons are locations of events recorded at YBI. The spatial dependence of empirical Green's functions was studied by Hutchings and $\mathrm{Wu}(1990)$, and they found that the variability in ground motion due to differences in source location and/or focal mechanism solutions are much less than those due to the site response. Hutchings (1991), Hutchings (1994), and Jarpe and Kasameyer (1995) found that interpolation for different source locations along a fault works quite well, and that source events do not have to fall directly along the fault of interest, but can be located near the fault. In synthesis, we have the option of correcting for different focal mechanism solutions, but Hutchings and Wu (1990) and Jarpe and Kasameyer (1995) found that, for high frequencies, corrections to empirical Green's functions do not improve the synthesis. Interpolation is performed by correcting for attenuation, geometric spreading by $1 /$ distance $(1 / R)$, and $P$ - and S-wave arrival times due to differences in source distance. We include the radiation pattern effect for low frequencies when we use synthetic Green's functions. A future borehole recording site will provide site specific ground motion.

\section{Calibration and Validation}

This modeling approach has been calibrated several times against data. First, we modeled waveforms of small earthquakes $(M=3.5)$ that have very well-known, independently determined source parameters (Hutchings 1994). Normalized cross-correlation values for the two events modeled at four stations each ranged from 0.56 to 0.85 . Hutchings (1991) also modeled the $M=6.4$ San Fernando earthquake at three sites. The fit to observed seismograms at two sites was within a factor of 2 in amplitude, and the phase and waveform information matched fairly well. The third station modeled did not have good calibration, and its amplitudes could not be checked; however, phase information matched well. Jarpe and Kasameyer (1996) performed a systematic validation of the modeling approach using Loma Prieta earthquake data. They fixed the moment, focal mechanism solution, slip distribution, and geometry from independent studies, 
and modeled the observed strong ground motion at 26 sites. They found that the standard error between observed and predicted response spectra is less than or equal to other methods for periods $0.05-2.0 \mathrm{~s}$. They also demonstrated a good match to observed waveforms.

The above validations were performed assuming that the source was well known. Hutchings (1991) and Foxall et. al. (1996) included the variability resulting from not knowing the source by modeling several rupture scenarios along a segment of the fault, and for a particular moment. Hutchings (1991) "predicted" strong motion parameters of peak acceleration and pseudo-velocity response at five sites that recorded the Loma Prieta earthquake. Hutchings utilized 25 rupture scenarios along the fault where the Loma Prieta earthquake occurred to account for the source variability from not knowing the source prior to the occurrence of the earthquake. The engineering parameters were predicted within the 16 and $84 \%$ log-normal standard errors at four of the five sites. The fifth site had recorded motion just above the one standard error value for both peak acceleration and pseudo-velocity response.

Foxall et. al., (1996) constrained the range of rupture parameters from independent arguments and synthesized a suite of ground motion for the Loma Prieta earthquake at the same 26 sites used by and Kasameyer (1996). They increased the number of scenarios computed until the variance of the engineering parameters stabilized. Lognormal average and one standard deviation values of peak acceleration, pseudo-velocity response spectra, and Fourier amplitude spectra are derived from the seismograms. Prediction uncertainty was obtained by (using the terminology of Abrahamson et al., 1990) by adding the variance form the 50 models run (parametric uncertainty) with the variance obtained by Jarpe and Kasameyer (modeling and random errors); they were added in quadrature. Engineering parameters of absolute acceleration response were predicted within the 16 and $84 \%$ log-normal standard errors at 24 of the 26 sites, and standard errors were reduced from Hutchings (1991). In addition, standard errors were less than or equal to standard empirical engineering studies even though source variability was maximized. This methodology provides a means to understand the range of ground motion variability due to the earthquake source, and introduces a probabilistic component to deterministic hazard calculations. 


\section{Near-Source Strong Ground Motion}

Locations very near fault rupture are dramatically affected by fault rupture velocity, fault slip rate, directivity, radiation pattern, and superposition of seismic waves. In addition, these effects are significantly different for ground displacements, velocities, and accelerations, as each of these has dominant energy at different frequency bands. Two terms describe aspects of ground motion near a fault. Near-source refers to distances within about 2 fault lengths of the earthquake. In this distance range, significant finite rupture effects are observed in strong ground motion and simple point source models of earthquakes are not sufficient. We account for these effects by modeling the complex evolution of the rupture. For example, the radiation pattern of shear waves works to enhance amplitudes of strong ground motion near a fault as the maximum amplitudes occur along the fault plane. Directivity due to fault rupture propagation also enhances or diminishes long period amplitudes. All these effects will be demonstrated below. Nearfield terms refer to wave arrivals that are recorded very near an earthquake and attenuate away at $1 / R^{2}$ and $1 / R^{4}$, and are a result of the effects of fault offsets. Near-field terms dominate within a fraction of a wavelength from the source, independent of rupture length. Near-field signals are typically long period in nature, and as discussed above, these terms are not included in the lower frequency synthetic Green's functions. Assessment of the importance of these terms for structural safety is the subject of future studies.

Near-source effects produce significant aspects of seismograms. One means to examine this effect is to study synthetic calculations of strong ground motion. Figures 3 and 4 show synthetic ground motion for the fault parallel (N145E) and fault-normal (N235E) components, respectively, of ground velocity at locations on the fault (Figure 3) and at the Stack (4.3 km distant, Figure 4). Only solutions with synthetic Green's functions are shown. For purposes of strong ground motion prediction, they are only considered reliable for frequencies less than $0.5 \mathrm{~Hz}$, but for analysis of near-field effects we examine frequencies less than $5.0 \mathrm{~Hz}$. The interpretation of Figures 3 and 4 is that the first large amplitude arrivals are made up of shear waves. These are followed by surface waves, which are primarily Love waves on the N235E component and Rayleigh waves on the N145E component (they are purely Love and Rayleigh waves for the $0 \mathrm{~km}$ distant solution). The shear wave radiation pattern has a maximum for locations along the fault and a nodal solution at points normal to the dislocation.

The amplitude of the first arriving shear wave (first arriving large pulse at about $10 \mathrm{sec}$ ) diminishes by a factor of 3 from locations on the fault to the location of the Stack. 


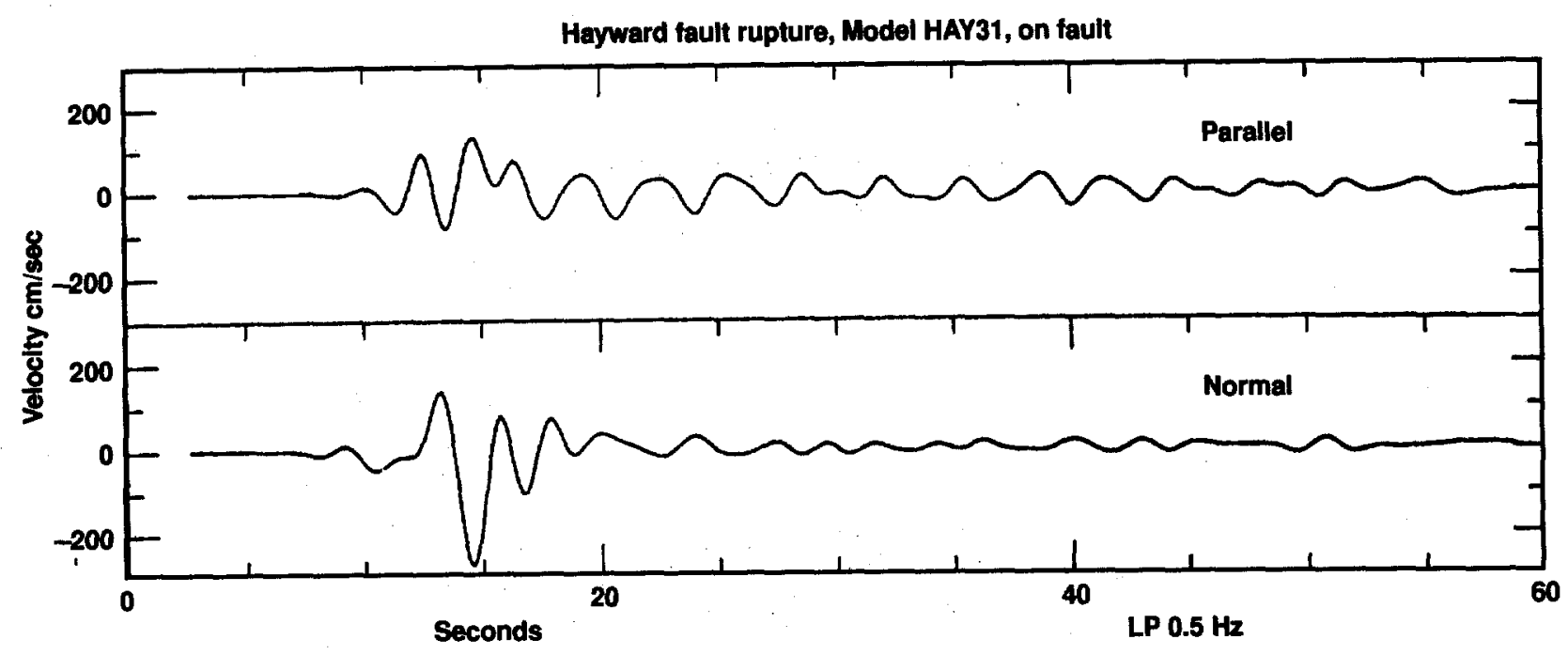

Figures 3. Synthetic ground motion for the fault parallel (N145E) components of ground velocity at locations on the fault.

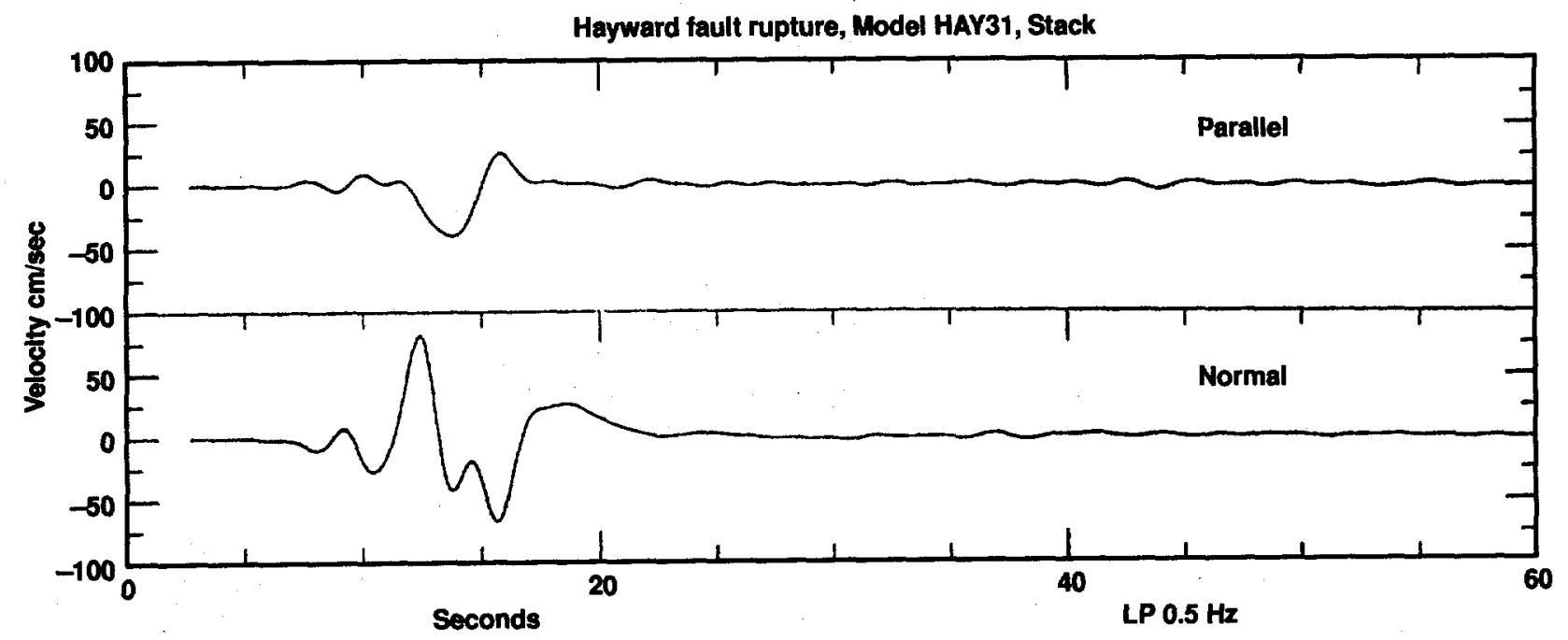

Figures 4. Synthetic ground motion for the fault-normal (N235E) components of ground velocity at locations at the Stack ( $4.3 \mathrm{~km}$ distant). 
The shear wave is presumably enhanced both by the directivity effect and the radiation pattern maximum along the fault. Rayleigh waves immediately follow the shear waves, and their amplitudes also diminish significantly away from the fault. Geometrical spreading is not considered a strong factor in the near-field ground motion, as large motion arrive from portions of the fault some distance up and down the fault strike, and radial distances are not greatly different for most of the fault surface. However, portions directly in-line with the sites are significantly affected by the geometrical spreading, and this would contribute a factor of $4.3 \mathrm{~km}$ at the Stack.

\section{Rupture Models}

The Hayward fault extends from Mission San Jose to northern San Pablo Bay (Figure 1). The working Group on California Earthquake Probabilities (1988 and 1990) have identified two segments of the Hayward that may rupture separately: the northern and southern segments. Both are considered capable of a magnitude 7.0 earthquake. In addition, the working group has posed the possibility of both segments rupturing during the same earthquake. The coordinate ends for the segments as defined by the working group (1990) plot the Hayward fault $4 \mathrm{~km}$ east of the mapped trace of the Hayward fault. Therefore, the latitudes provided by the working group are used to segment the fault, but the longitude is obtained from mapped surface traces: $37.500^{\circ} \mathrm{N} 121.935^{\circ} \mathrm{W}$, $37.733^{\circ} \mathrm{N} 122.137^{\circ} \mathrm{W}$ for the southern segment, and extending to $38.117^{\circ} \mathrm{N} 122.472^{\circ} \mathrm{W}$ for the northern segment. The extension of the northern segment through San Pablo Bay has been supported by recent high resolution seismic profiles and seismicity (Lienkaemper et al., 1989). The Working Group did not consider the Hayward fault south of Mission San Jose capable of large earthquakes. Surface expression of the fault is weak or nonexistent and has very little microearthquake activity. The segments are shown in Figure 1. These segments are 50 and $32 \mathrm{~km}$ long, respectively. We have modeled the northern segment earthquake as $M=7.1\left(M_{0}=5.0 \times 10^{26}\right.$ dyne-cm) with $2.0-\mathrm{m}$ average slip (strain release) and the southern segment as $M=7.0\left(M_{0}=3.5 \times 10^{26}\right)$ to keep average slip equal for the two segments. The combined Hayward fault earthquake is modeled a $M=7.25$ event $\left(M_{0}=8.5 \times 10^{26}\right)$ with $2.1-\mathrm{m}$ average slip. We are using the characteristic earthquake model (Schwartz and Coppersmith, 1984; and Sieh, 1984) to project the magnitude of the combined rupture as a linear sum of the segments.

Two earthquakes occurred along the Hayward fault in the past century (1836 and 1868), and both have been estimated by the working Group to have magnitude about 7.0. 
Slip rate estimates of about $9 \mathrm{~mm} / \mathrm{yr}$ result in $1.4 \mathrm{~m}$ of accumulated strain since 1836 for the northern segment. This number is within the range that is possible within the near future (Wells and Coppersmith, 1994).

\section{Strong Ground-Motion Prediction}

First, we evaluated the difference in hazard to the Stack from either rupture of the northern segment of the Hayward fault or rupture of the full Hayward fault.

Considering the constraints imposed on potential fault rupture, we generated a suite of twenty potential rupture scenarios for each earthquake and computed the commensurate strong ground motion. To develop scenarios, we used a computer program that randomly varied rupture parameters within prescribed constraints. Lognormal average and one standard deviation values of peak acceleration, pseudo velocity and absolute acceleration response spectra are derived from the suite of synthesized strong ground motion. The median and plus one standard deviation values for peak acceleration are 0.36 and $0.84 \mathrm{~g}$ for the $M=7.25$ earthquake and 0.38 and $0.74 \mathrm{~g}$ for the $M$ $=7.1$ earthquake. The $M=7.25$ earthquake has larger values for pseudo velocity response and absolute acceleration response than the $M=7.1$ earthquake at most periods. The pseudo-velocity and acceleration response values were significantly greater for periods greater than $2 \mathrm{sec}$. With these results, the $M=7.25$ full rupture of the Hayward fault was identified as the most hazardous to the site.

We conducted a more comprehensive analysis of the hazard from the $M=7.25$ earthquake. We generated a suite of 100 rupture scenarios for this earthquake and computed the commensurate strong ground motion. To develop scenarios, we again used a computer program that randomly varied rupture parameters within prescribed constraints. Moment, geometry, rigidity model, and slip vector were held fixed. We varied six parameters: hypocenter, rupture roughness, rupture velocity, healing velocity, asperity number, and asperity location. These are parameters that significantly affect the synthesized ground motion and are physical parameters, whose value cannot be determined prior to an earthquake. They have also been found in past research to be significant to strong ground motion (Hutchings, 1991 and 1994; Foxall et al., 1996). By varying the rupture parameters within prescribed limits, we attempt to span the range of possible scenarios of potential earthquakes. Whether we are able to span the full range of potential ground motion has been studied in some detail by Foxall et al., (1996), and is discussed below. They found that after about 20 scenarios, the full range of calculated 
absolute acceleration response was achieved, and that the predicted range included the observed values of absolute acceleration response in 24 of 26 sites that recorded the Loma Prieta earthquake. Table 1 lists the rupture parameter values used. The parameter constraints in Table 1 and others not listed in the table are as follows:

MODEL is the scenario identifier.

ASPERITIES are included to add variation to the slip distribution. The slip distribution for asperities is added to the main rupture. Asperities have a circular shape and have a diameter randomly chosen to be between 0.2 and 0.8 times the fault width. The number of asperities is randomly chosen to be between 0 and 6 . Six was arbitrarily chosen as the maximum number from the fault length divided by its width. Asperities are not allowed to overlap. The asperity numbers listed in Table 1 are specific to the model; asperities are randomly selected for each scenario. Stress drop in asperity portions of the rupture are higher than other portions of the rupture area. Figure 5 shows the location of all asperities for the one hundred models.

ROUGHNESS (\%) is the percentage of the rupture surface for which we applied randomness to the rise time so that we could simulate roughness. The percentage is randomly selected to be either $0,10,20,33$, or $50 \%$. This percentage of elements has rise time randomly shortened to between 0.1 and 0.9 times the original value. The difference in rise time is applied as a delay to rupture initiation so that the rupture reaches the full value at the original time. Areas of roughness have corresponding high stress drop.

MOMENT is constrained to be $8.5 \times 10^{26}$ dyne-cm for the total rupture, including asperities. However, the moment of asperities is randomly selected. Their moment is constrained such that the maximum displacement is between 5 and $10 \mathrm{~m}$.

HYPOCENTER is constrained to occur at least one kilometer from the fault ends, $2.0 \mathrm{~km}$ from the lower limit of the fault, and at depth $>7.5 \mathrm{~km}$. The limit at the ends is due to a physical model that has at least a small amount of bilateral rupture. The limit at the lower portion of the fault is because the material greater than $13-\mathrm{km}$ depth is modeled as weakening in rigidity as the aseismic zone is approached, and the limit to $>7.5 \mathrm{~km}$ is due to the observation that past earth- 


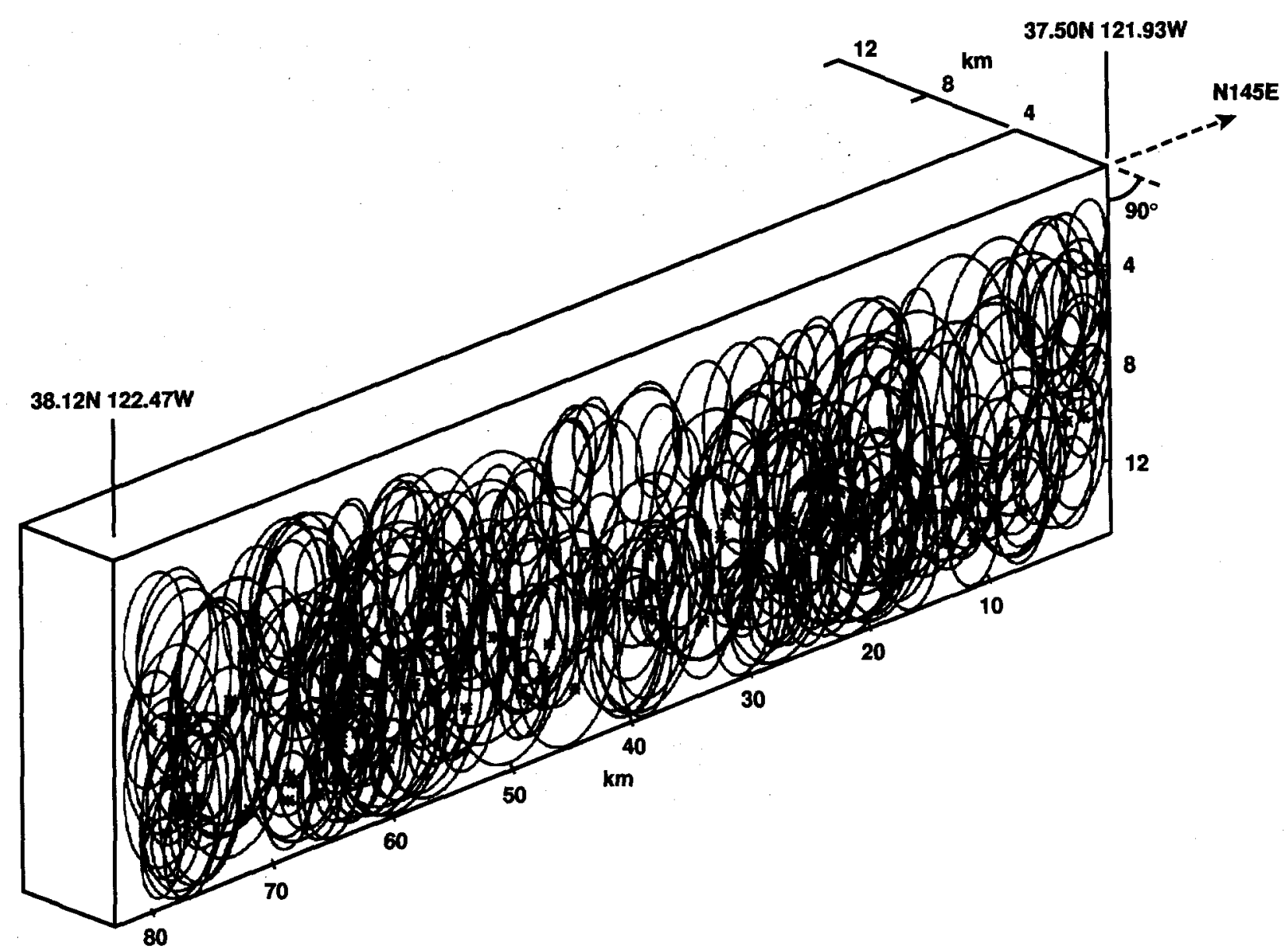

Figure 5. The location of all asperities and hypocenters for the one hundred models.

quakes originate at depth (Sibson, 1982; Tse and Rice, 1986). Figure 5 shows the location of all hypocenters for the one hundred models.

RUPTURE VELOCITY (xVs) is the percentage of shear-wave velocity for the rupture velocity. This was allowed to vary from 0.75 to 1.0 times the shear wave velocity. This is the range from the Rayleigh to shear wave velocity.

HEALING VELOCITY ( $\mathrm{xVr}$ ) is the percentage of the rupture velocity for the healing velocity. Healing velocity controls the rise time. It is the shortest time for the rupture front to reach an edge and travel to a point at the healing velocity. If the healing velocity is greater than the rupture velocity, it will shortly overtake the rupture front, and thus, no rise time will develop. Clearly, the simple crack model for healing velocity is not sufficient, i.e., with healing at 0.6 to 1.0 times the Pwave velocity. Therefore, we randomly varied healing velocity to between 0.8 and 1.0 times the rupture velocity, which is between the Rayleigh wave velocity and 
the shear wave velocity. In addition, the surface is not allowed to be a healing boundary for rupture since significant seismic pulses, which are necessary to shut down slip, are not generated from the surface (discussed below) (Das and Kostrov, 1989; and Schultz, 1990). Also, the time of propagation from hypocenter to an element utilized in the Kostrov slip function is limited to less than or equal to the shortest distance to a fault edge from the hypocenter divided by the rupture velocity. This is somewhat arbitrary, but limits the linear growth of displacement with rupture distance for very long ruptures. We equate this limiting value to a limit of "memory" of fault rupture and a departure from a pure crack solution for an extended rupture.

STRESS DROP is a dependent variable derived from the Kostrov slip function and allowed to vary due to two other effects modeled in rupture. First, asperities are allowed to have a different stress drop than surrounding portions of the fault rupture. Second, stress drop is constrained to diminish near the surface of the earth at the rate of $10+0.75 x$ the confining pressure due to the lithostatic load ( 300 bars at $1.7-\mathrm{km}$ depth). The minimum of this and the full rupture stress drop is used. Initially, the full rupture stress drop (without asperities) is assumed to be 300 bars, then the slip and rise times are computed over the fault surface (including asperities). If the moment is different than prescribed, the stress drop is adjusted to give the slip amplitudes necessary. The rise time is not adjusted.

RIGIDITY varies with the shear wave velocity over all depths except it diminishes at the same rate as the stress drop near the surface. The diminishing of stress drop and rigidity near the surface has two effects. First, reducing the rigidity results in very little moment contribution for rupture near the surface. Second, the commensurate diminishing of stress drop and rigidity result in significant displacements (although not significantly seismogenic) at the surface.

SLIP VECTOR is constrained to $180^{\circ}$ for a right-lateral strike slip fault.

Figure 6 shows displacement contour plots of two of the one hundred scenarios; plots of two other scenarios are shown in Figures 14 and 16. It is apparent that the slip distribution varies considerably between different scenarios. It is also apparent that the number of asperities varies considerably. The location of the asperity relative to the site can cause high slip to be close to the site. 


\section{Error Analysis and Variability}

We assume the following: the scenarios are all of equal probability, the hazard to the structure is monotonic with response spectra, and the scenarios were randomly selected within the bounds of possible rupture parameters. Values for spectra discussed here are the average of the log of the two horizontal components, or the log of the vertical component. In the terminology of Abrahamson et al.,1990, our prediction uncertainty has two elements: (1) parametric uncertainty, which arises from uncertainty as to which scenario will occur, and (2) modeling and random errors caused by not modeling the actual rupture process correctly, and by factors such as uncertainties in moment estimates for empirical Green's functions and errors caused by the interpolation of source events along the fault surface.

We calculate the combined effect of the prediction errors. Parametric uncertainty is included in the calculation of many rupture scenarios. Random errors due to moment estimates of source events of empirical Green's functions are averaged out by using several source events for empirical Green's functions. Random errors resulting from the interpolation of empirical Green's functions is unknown for the Stack. Modeling errors from not calculating a particular scenario correctly are considered minimal since Hutchings (1994) was able to compute observed records very closely when the scenarios were well constrained by independent means [see figures 9 and 10 in Hutchings (1994)].

Jarpe and Kasameyer (1996) estimated the second element of uncertainty, modeling and random errors, by comparing computed and observed records for the 1989 Loma Prieta earthquake, whose independent parameters were well determined. This error for the Stack is assumed to be equal to the 1 standard deviation value obtained by Jarpe and Kasameyer (1996). The total source uncertainty is characterized by adding the parametric and "random plus modeling" standard deviation estimates in quadrature.

We also assume that spectral values are log-normally distributed. Figure 7 shows the absolute acceleration response spectra (average for two horizontals) computed from accelerograms from the one hundred scenarios. The accelerograms were computed for frequencies 0.0 to $5.0 \mathrm{~Hz}$. Time and computer limitations prohibited computing accelerograms out to $33.0 \mathrm{~Hz}$. Instead an average source model was used to calculate an accelerogram for frequencies 5.0 to $33.0 \mathrm{~Hz}$ for these calculations. This accelerogram was merged with the accelerograms from the one hundred models. The accelerograms were merged because response spectra are sensitive to frequencies other than those of each individual 

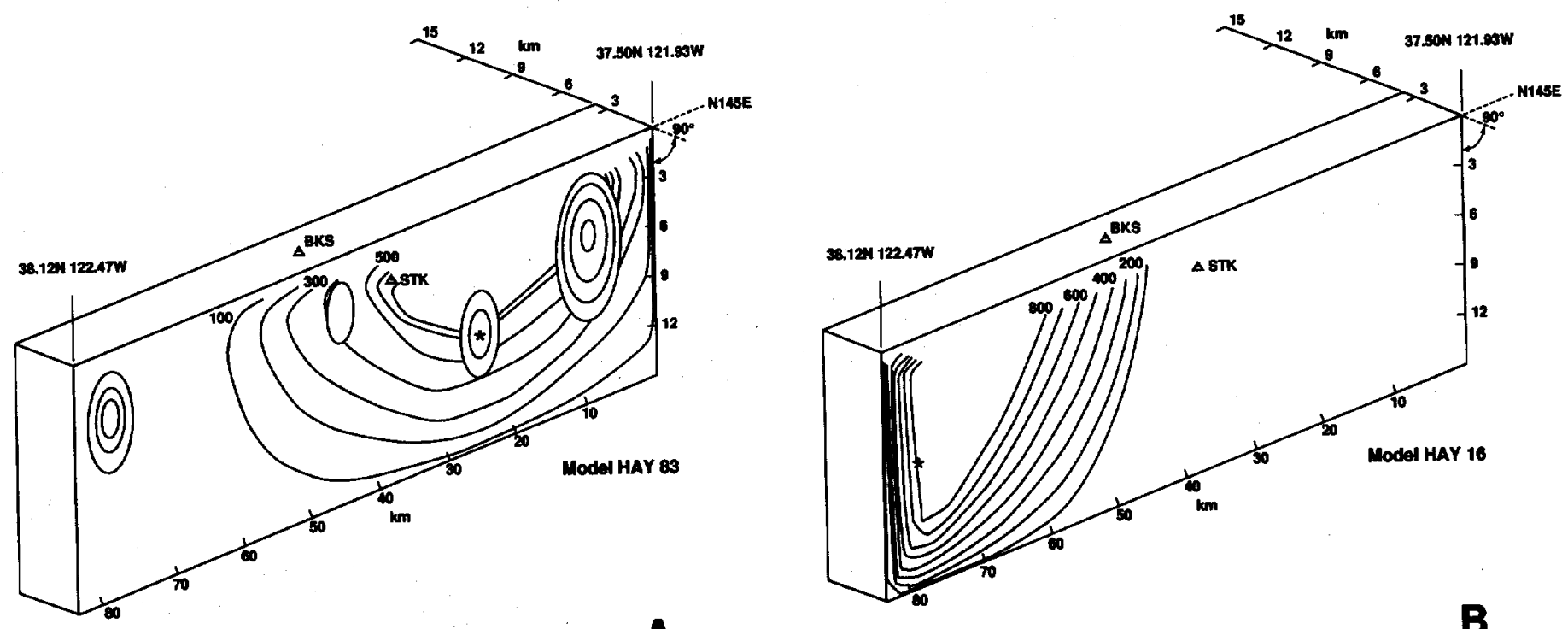

A

Figure 6. Displacement contour plots of various scenarios. The slip distribution varies considerably between the different scenarios.

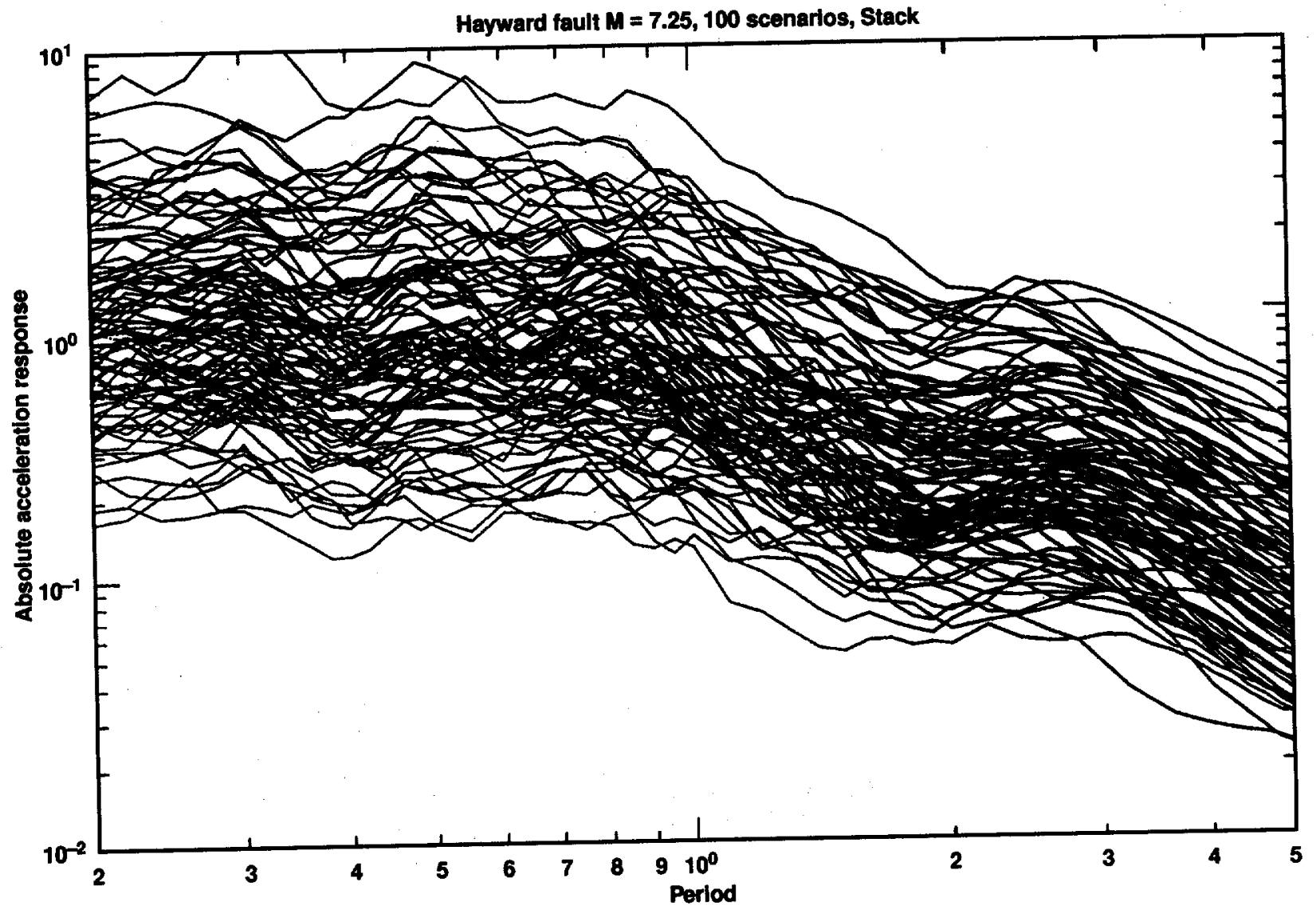

Figure 7. The absolute acceleration response spectra (average for two horizontals) computed from accelerograms from the one hundred scenarios. 
single-degree of freedom oscillator. Figure 8 shows the distribution of the natural log of the calculated AARS value at a period of $0.5 \mathrm{sec}$. The histogram is not quite symmetrical, but is sufficiently close (by eye) that we will assume the calculated AARS are log normally distributed. Figure 9 shows the log-normal mean (arithmetic median), and plus and minus one standard deviation absolute acceleration response spectra values (16 and $84 \%$ confidence limits) from the one hundred scenarios. The confidence limits include the parametric and "random plus modeling" error estimates discussed above.

\section{Variability}

Figure 10 shows how the mean and one standard deviation values changed with the number of scenarios that were run. Values are for AARS at $0.5 \mathrm{sec}$ period. Clearly the values have stabilized after 20 runs, but continue to change.

Using the log-normal assumption, we can estimate the uncertainties involved in representing the population mean and variance by the sample mean and variance, as a function of the number of scenarios $(n)$ used to calculate the sample mean and variance. All statistics are in log-normal space.The standard deviation of the mean is estimated by taking he standard deviation of that sample and dividing by the square root of $n$. Noting that the sample variance is distributed as chi-squared, it can be shown that the uncertainty in estimating the population variance can be estimated by the actual variance divided by $(n-1)$. Figure 11 shows the \pm 1 standard deviation estimates for the mean and (mean +1 standard deviation) values as a function of $n$. Figure 12 shows the same values, but with the assumption that the uncertainties in the mean and standard deviation added in quadrature. The \pm 1 standard deviation range for the AARS corresponds to a range of 1.90 $2.46 \mathrm{~g}$ for the AARS at this period. That range is an estimate of how different the answer might be for a completely independent run of scenarios. Running 1000 scenarios would reduce this range to about $\pm 0.1 \mathrm{~g}$, if our statistical approximations are valid.

\section{Hazard}

The hazard is defined here as either the median or the $84 \%$ of the suite of all possible response spectra. Figure 13 shows the median (log-normal mean), \pm 1 standard deviation response spectra from the 100 rupture scenarios. Model HAY31 generated time histories that most closely match the +1 standard deviation value (Figure 13). Figure 14 shows the slip distribution and hypocenter of scenario HAY31. There is one small 


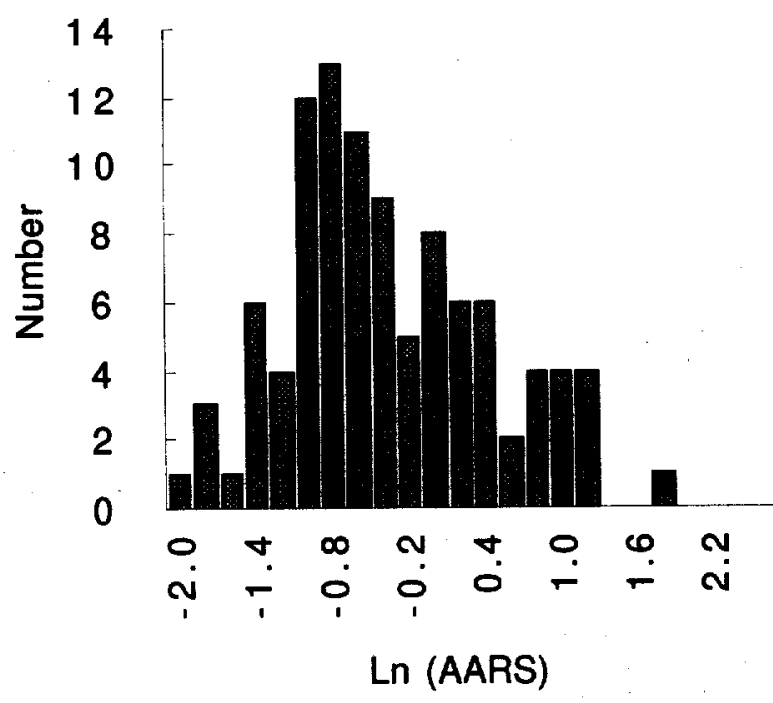

Figure 8. The distribution of the natural $\log$ of the calculated AARS value at a period of $0.5 \mathrm{sec}$.

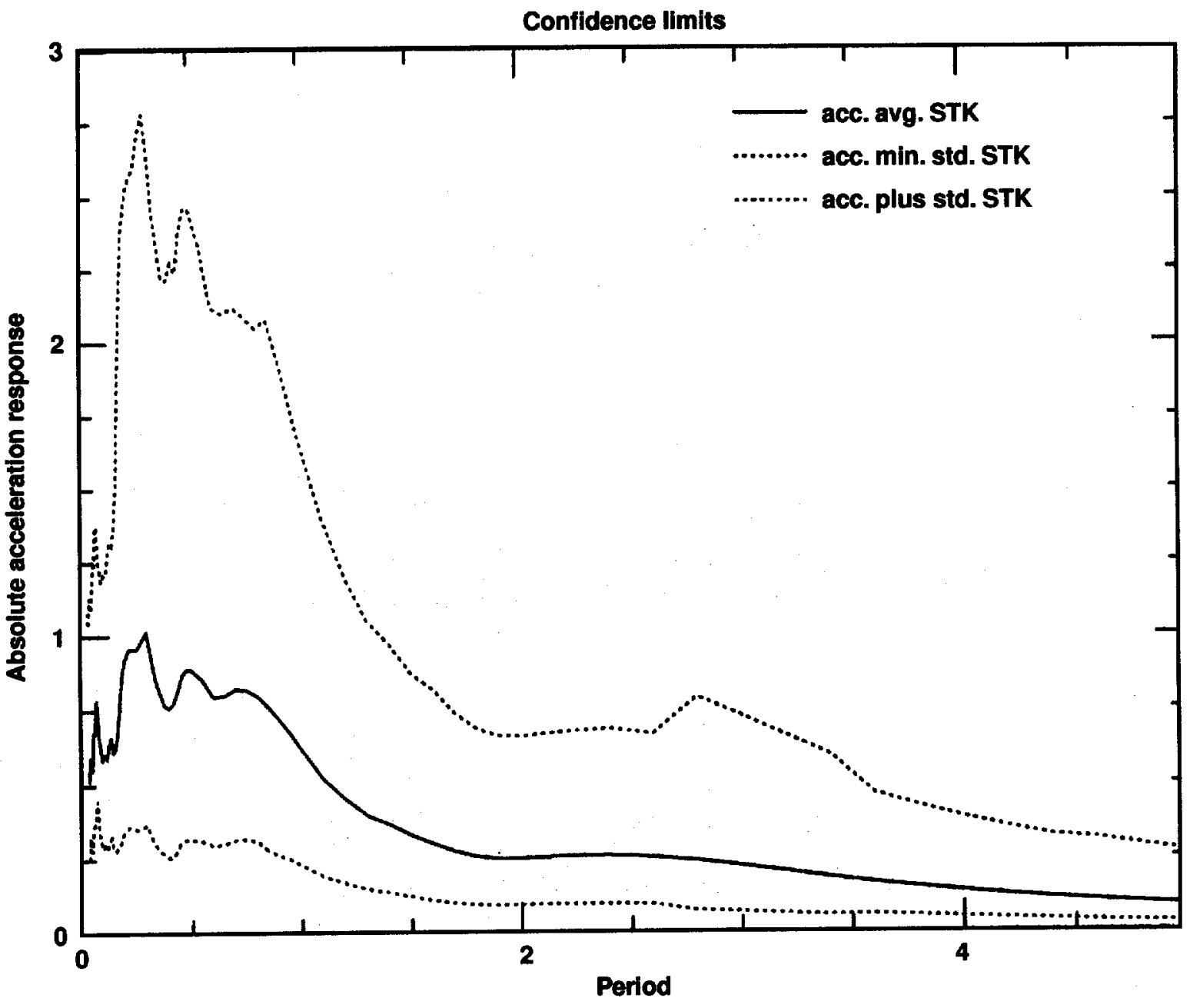

Figure 9. The log-normal mean (arithmetic median), and \pm 1 standard deviation absolute acceleration response spectra values ( 16 and $84 \%$ confidence limits) from the one hundred scenarios. 


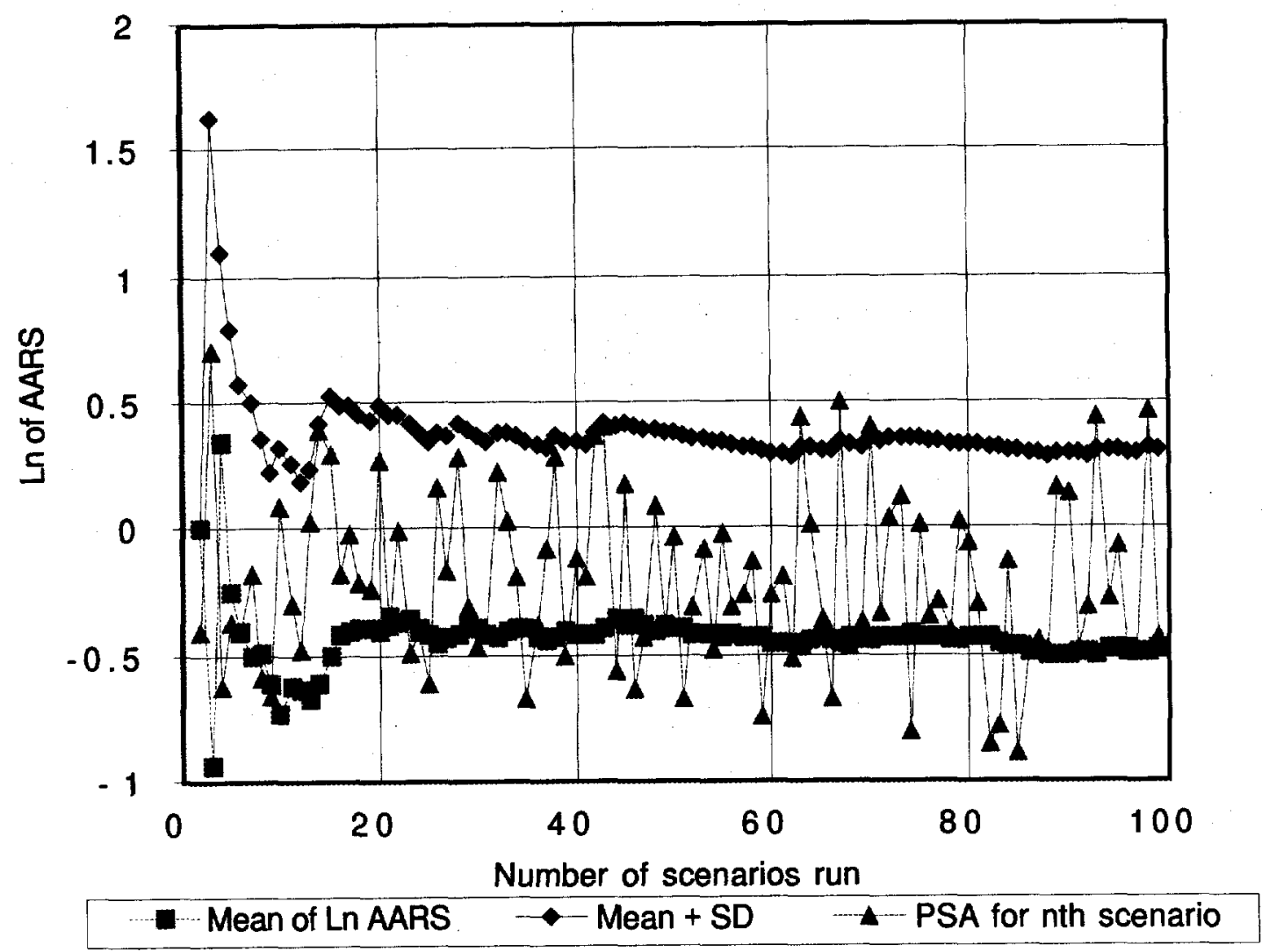

Figure 10. Changes in the mean and one standard deviation values as the number of scenarios increased.

asperity at the hypocenter for this model. Figure 15 shows the time histories; the top three are the three components of acceleration, the middle three are the same records integrated to displacement, and the bottom three are the displacement values. This time history accelerogram is for frequencies 0.05 to $33.0 \mathrm{~Hz}$. The solution from $5.0-33.0 \mathrm{~Hz}$ was obtained from a synthesis using empirical Green's functions obtained from BKS and YBI, so that frequencies $0.05-0.5$ were computed with synthetic Green's functions, frequencies $0.5-5.0$ were computed with empirical Green's functions from station BKS, and frequencies $5.0-33.0 \mathrm{~Hz}$ were computed with empirical Green's functions from station YBI (source model 2003 was used for frequencies 14.0-33.0 with model m2003).

Model HAY06 generated time histories that most closely match the median response spectrum (Figure 13). Figure 16 shows the displacement contours and hypocenter for model HAY06. There are two asperities for this model, one at the hypocenter and one between 70 and $80 \mathrm{~km}$ near the bottom of the fault. Figure 17 shows the time histories; the top three are the three components of acceleration, the middle three are the same records integrated to displacement, and the bottom three are the displacement values. 
Uncertainty in mean of AARS at $0.5 \mathrm{sec}$.

Shows how uncertainty decreases with number of scenarios run.

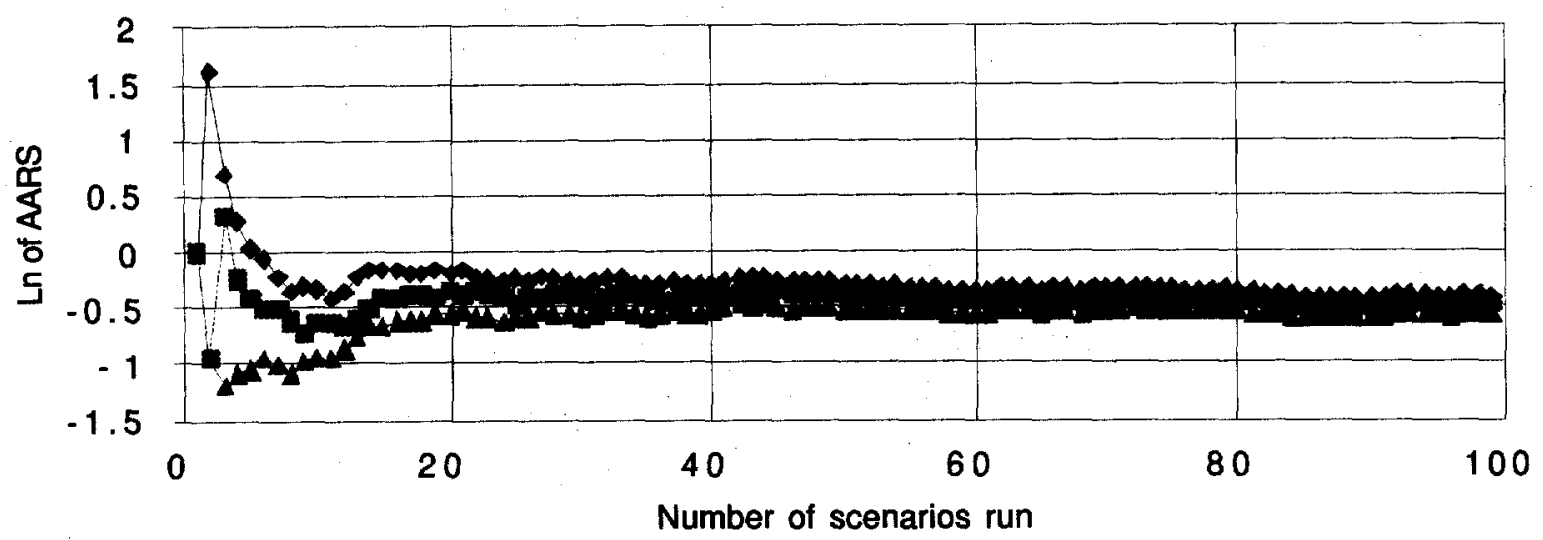

Mean of Ln AARS $\rightarrow-$ Mean + SD of the mean $\rightarrow-$ Mean - SD of the mean

Figure 11. The \pm 1 standard deviation estimates for the mean and (mean +1 standard deviation) values as a function of $n$.

Uncertainty in Mean + SD at 0.5 sec.

Shows decrease in uncertainty as more scenarios are run.

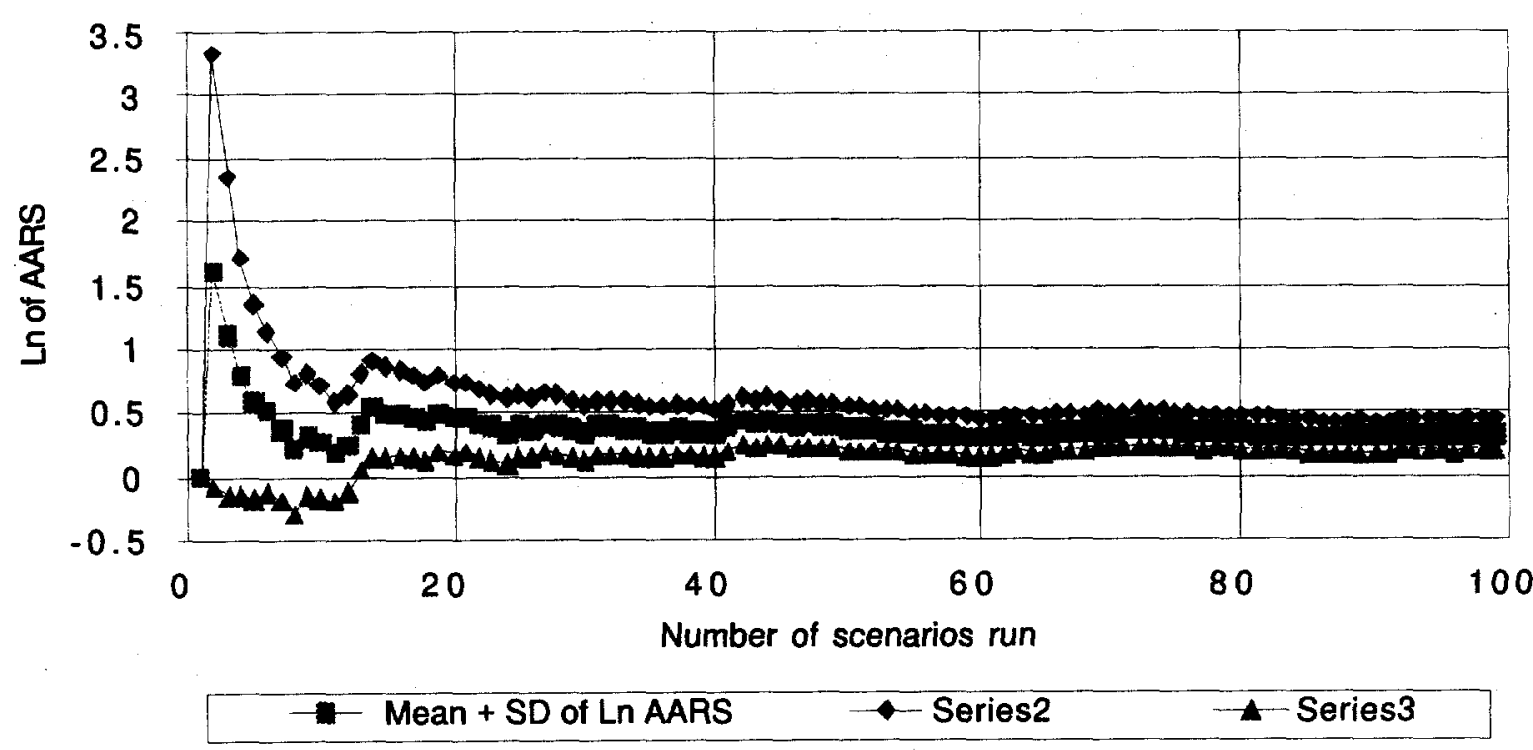

Figure 12. The same values as Figure 11, but with the assumption that the uncertainties in the mean and standard deviation added in quadrature. 


\section{Discussion and Conclusions}

The median and one standard deviation time histories shown in Figures 15 and 17 have significant differences. These differences are due to the different rupture models. Model HAY31, which is the one standard deviation model, has high slip amplitude mostly in the northern portion of the fault and has a strong directivity effect as rupture propagates from the hypocenter towards the site. This contributes to the higher ground motion. The rupture velocity is also relatively high $(0.94 \mathrm{xVr}$, Table 1$)$, which also added to higher amplitudes. Model 06, which is the median model has slip more evenly distrib-

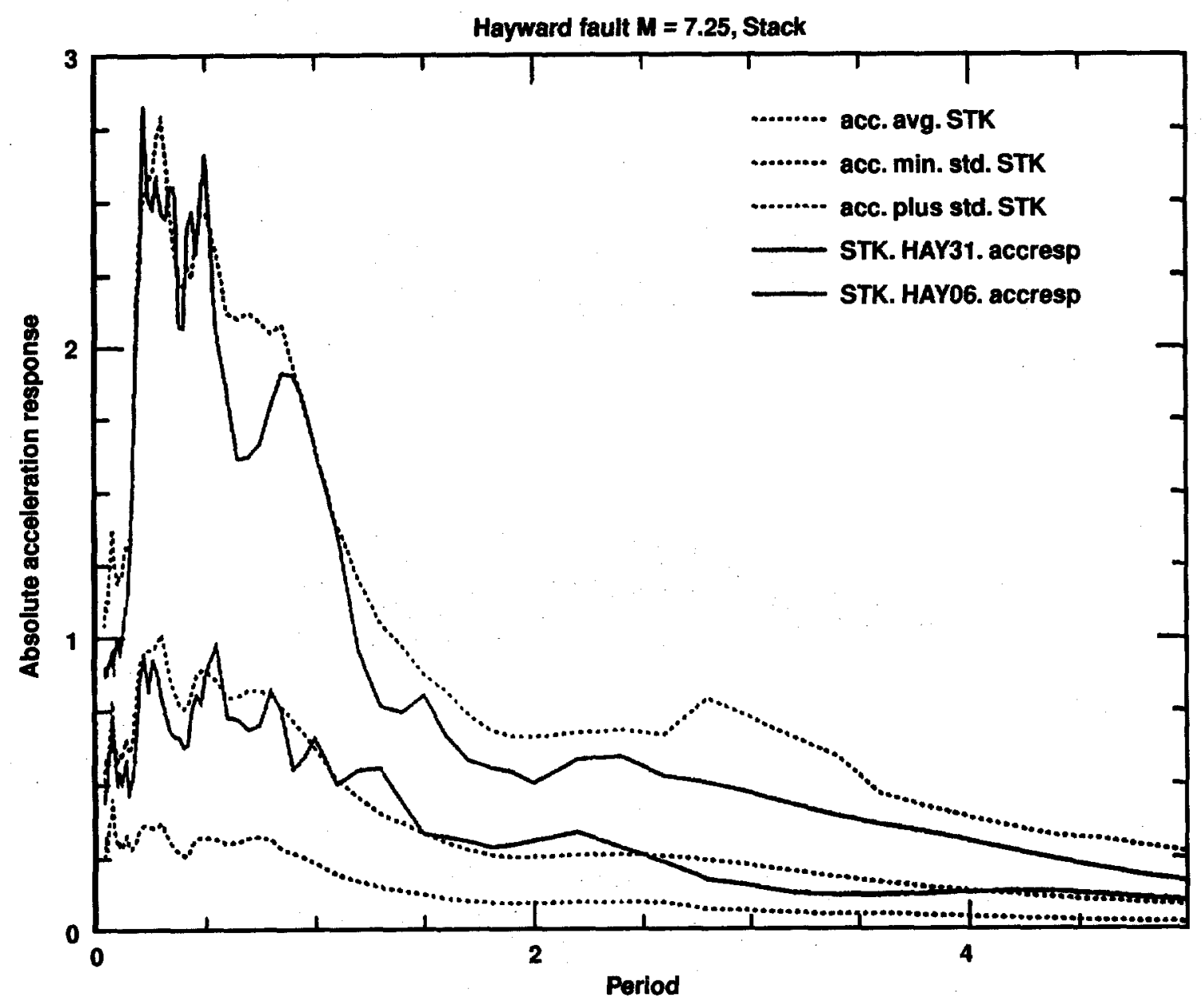

Figure 13. The median (log-normal mean), \pm 1 standard deviation response spectra from the 100 rupture scenarios. Model HAY31 generated time histories that most closely match the +1 standard deviation value. 


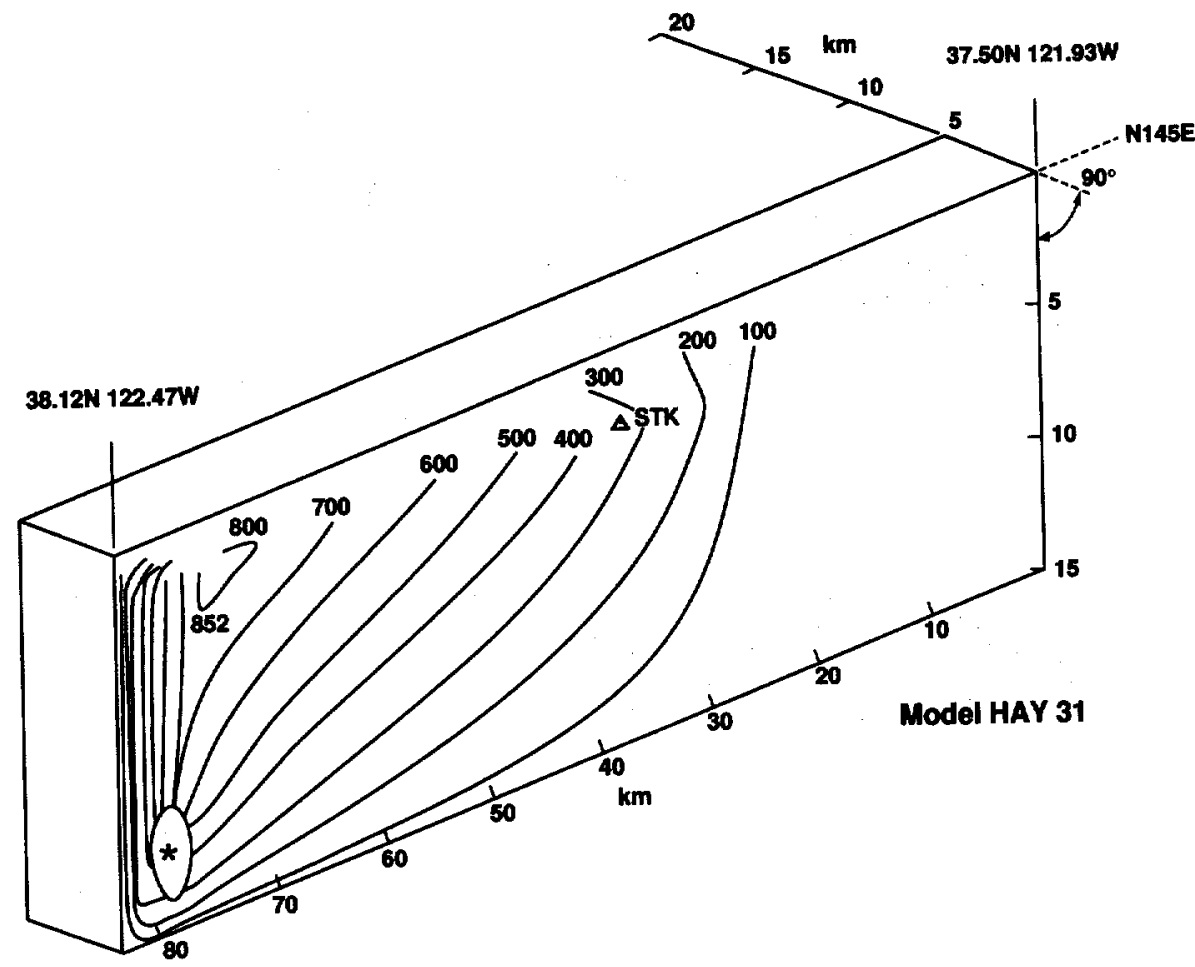

Figure 14. The slip distribution and hypocenter of scenario HAY31. There is one small asperity at the hypocenter for this model.
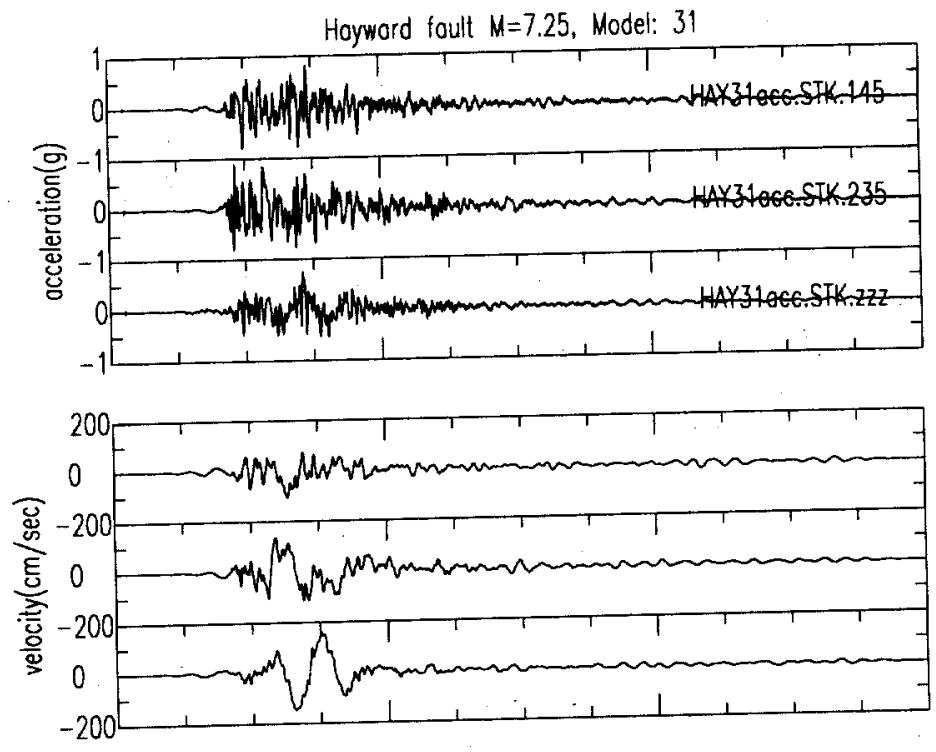

Figure 15. Time histories for frequencies 0.05 to $33.0 \mathrm{~Hz}$; the top three are the three components of acceleration, the middle three are the same records integrated to displacement, and the bottom three are the displacement values.

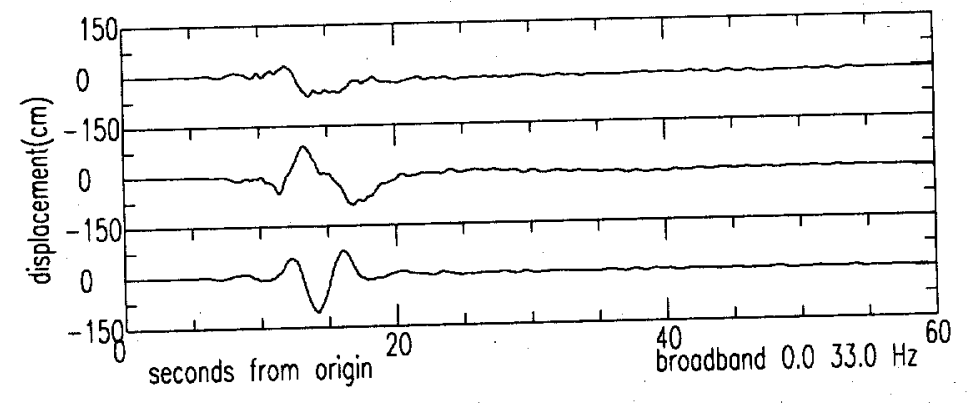


uted throughout the fault and with lower amplitudes; the rupture has more a bilateral effect relative to the site; it has asperities, but they are located away from the site; and, the rupture velocity is lower $(0.77 \mathrm{xVr})$. The peak accelerations for the two models are 0.86 and $0.41 \mathrm{~cm} / \mathrm{sec}^{2}$, for models HAY31 and HAY06, respectively.

The ground velocity is higher from model HAY31 than from HAY06 (Figures 15 and 17, middle traces), with peak values of 158 and $81 \mathrm{~cm} / \mathrm{sec}$, respectively. This is due to the long period velocity pulse, which is larger for model HAY31 because of a stronger directivity effect. Also, the long period pulse is more pronounced for different components from the two models. For model HAY31, the pulse is more pronounced on the $\mathrm{N} 235 \mathrm{E}$ and vertical components. While, for model HAY06, the pulse is more pronounced on only the N145W component. The directivity effects are different because of the different locations of the hypocenters.

The ground displacements are more similar for the two models HAY31 and HAY06 (Figures 15 and 17, bottom traces), with peak values of 106 and $86 \mathrm{~cm}$, respectively. This is because this effect is more due to the final offset of rupture, which is more similar for locations near the site from the two models.

Strong ground motion at locations less than about $5 \mathrm{~km}$ from large earthquakes have not been well sampled from past earthquakes. The empirical data base consists of 6 recordings from $M \geq 6.9$ earthquakes (Table 2), and this sparse data base makes synthesis of strong ground motion imperative. It is apparent from Table 2 that the scatter in observations is about a factor of 4 . The scatter in engineering parameters from this study are about a factor of 10 (excluding a few outliers). The difference between the two scatters' values may be because there are too few observations of actual earthquakes to capture the variability that may actually occur, or the method utilized here to synthesize ground motion includes too wide a variation of parameters. Further research and additional recordings of large earthquakes are necessary to resolve this question.

\section{Comparisons with Kobe Records}

Figure 18 shows peak acceleration and peak velocity values from the $M=6.9,1995$ Kobe earthquake, along with values for scenarios HAY31 and HAY06 for the $M=7.25$ Hayward fault earthquake. These values are those obtained after the soils modeling has modified the input values obtained from this report. Notice that the values predicted from this report fit very well with values recorded from Kobe. Figure 19 shows the location of two sites that recorded high acceleration response values. From Figure 18, notice that the peak velocity values exceed those predicted by standard attenuation relations. 

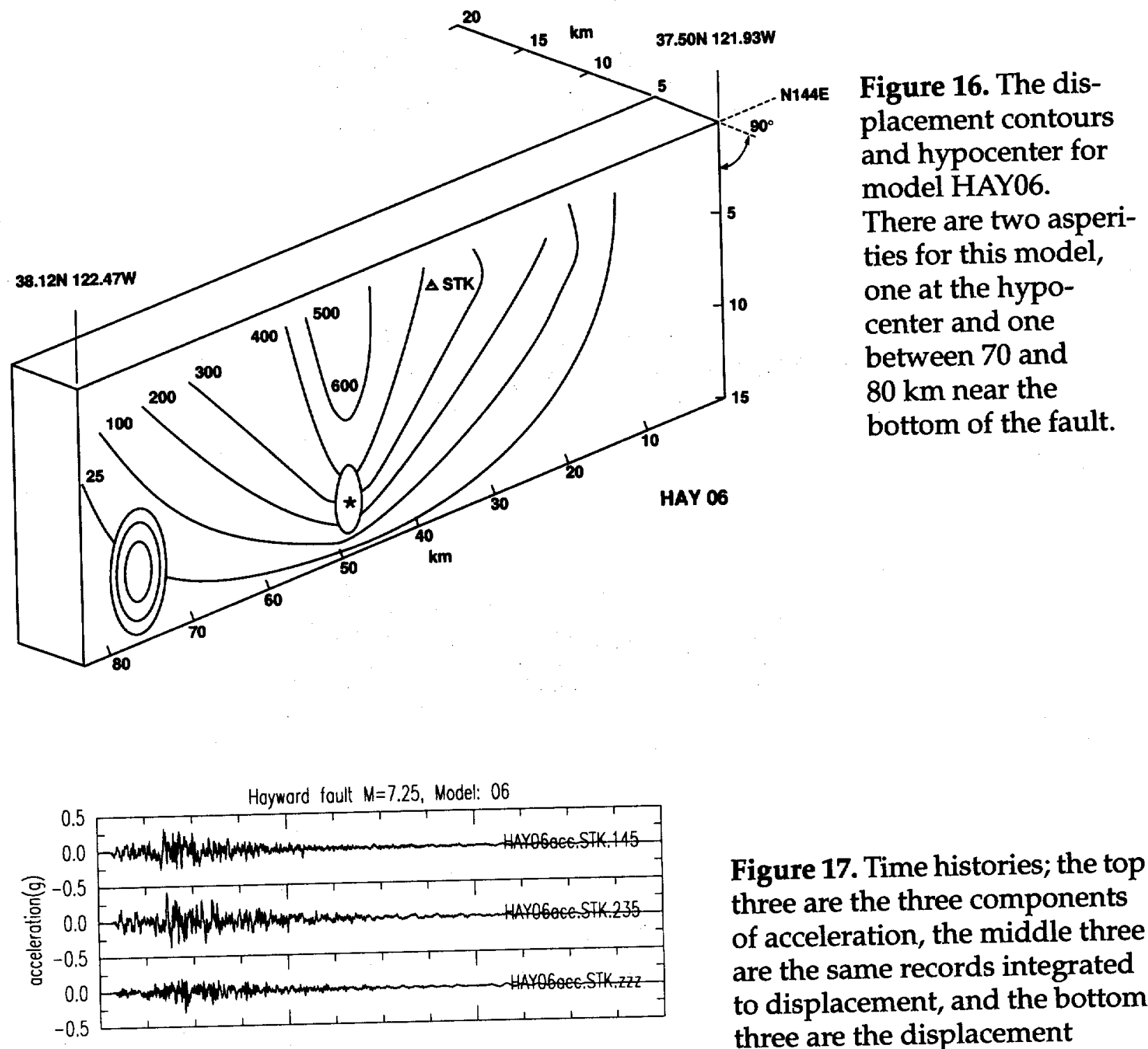

Figure 17. Time histories; the top three are the three components of acceleration, the middle three are the same records integrated to displacement, and the bottom three are the displacement

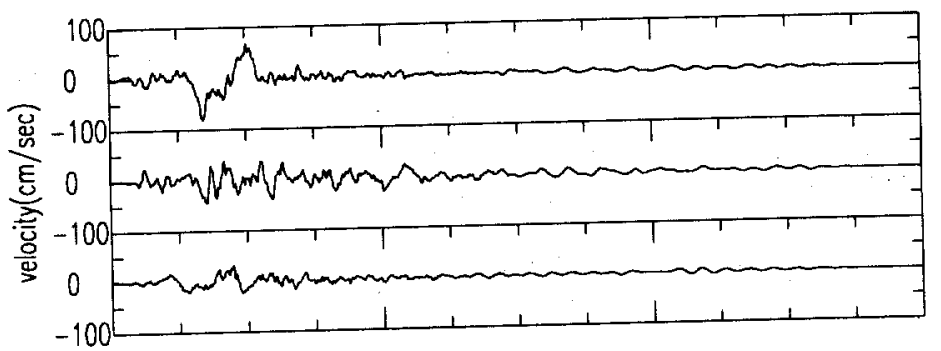
values.

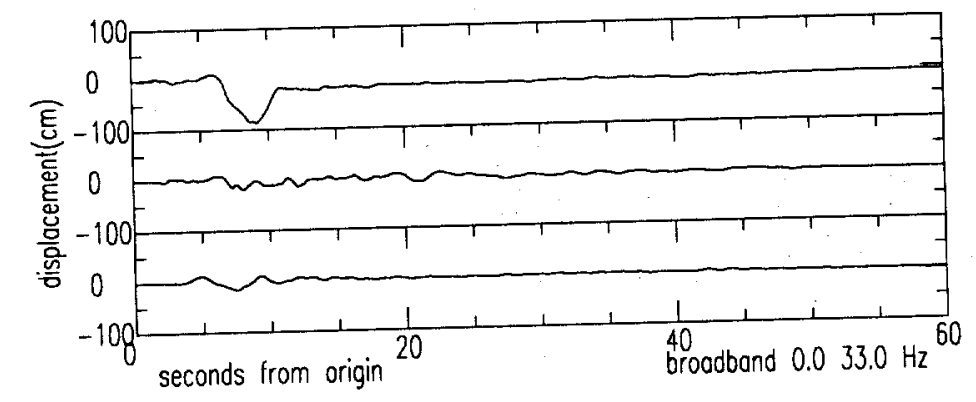


Peak velocity from scenario HAY31 overlays with that recorded at the same distance from the Kobe earthquake.

Since STK is very near the fault, one might expect a large fault normal component in long periods. This is evident in the velocity and displacement records in Figure 15, where the top trace is aligned fault parallel and the second is trace is fault normal. Notice that the vertical component also has a large velocity and displacement pulse. This is considered to be due to propagation up dip. Table 3 lists fault normal and fault parallel values of peak acceleration and velocity from records of the 1995, $M=6.9$ Kobe earthquake at Takatori, which has the same distance from the fault and has a similar geometrical relationship to the fault as STK. Also listed are the values from Lucerne site adjacent to the 1992, $M=7.3$ Landers earthquake, which is at a comparable distance and geometry as site BKS (Hutchings, 1996). It is apparent that the results at these two sites are close to those obtained from actual recordings.

Figures 20 and 21 show absolute acceleration response spectra at the same two sites discussed above from the Kobe earthquake, and the absolute acceleration response values from the comparable sites discussed above for this study. The bedrock accelerograms have been propagated through a soils model to get comparable surface records. It is apparent that the absolute acceleration response values obtained from synthesized records are comparable to those obtained from the Kobe earthquake.

It is apparent that the methodology used in this study captures some of the same effects observed in the Kobe earthquake, and this contributes to the reliability of the synthesized records for the Hayward fault earthquake. 

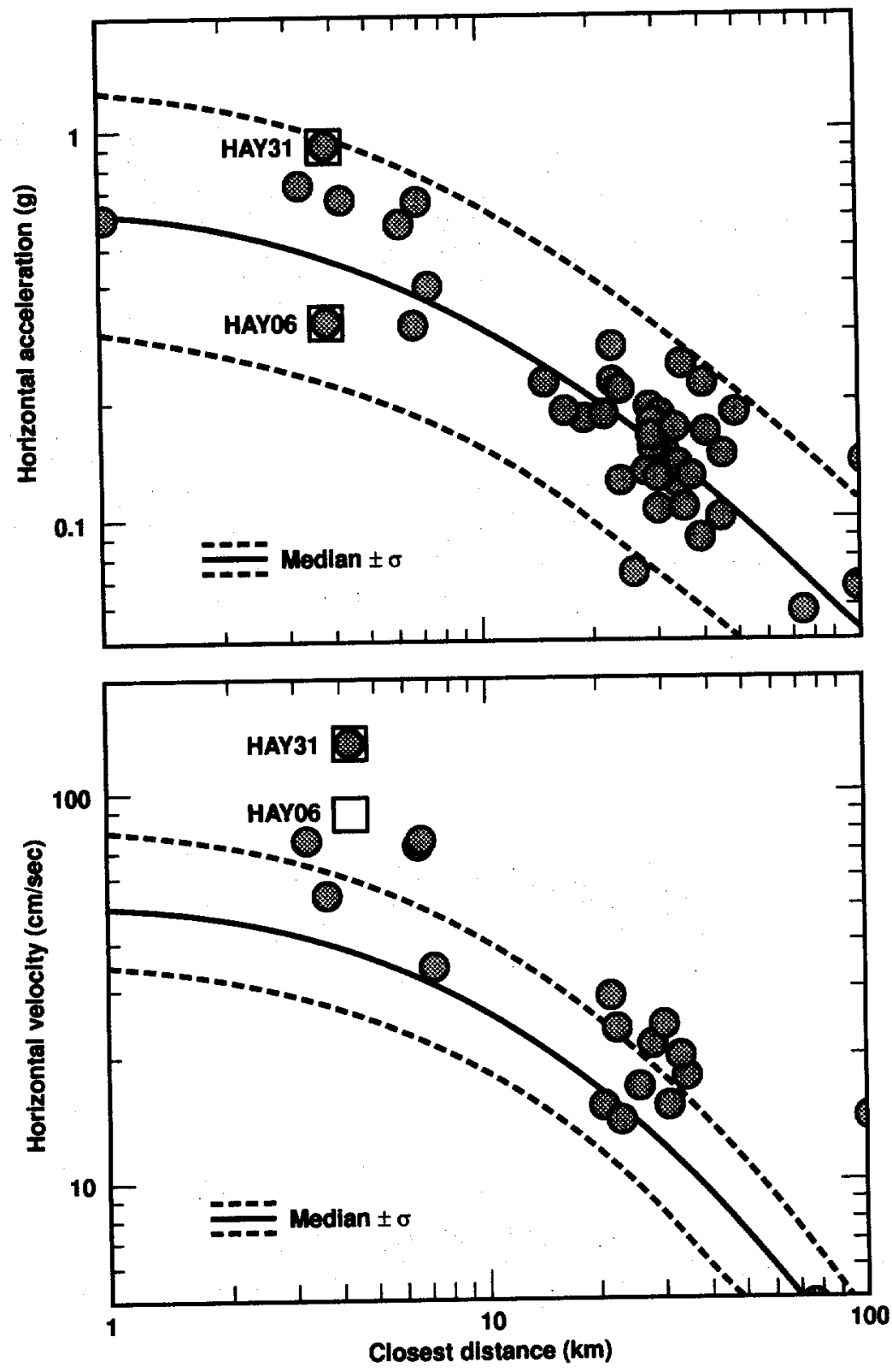

Figure 18. Peak acceleration and peak velocity values from the $M=6.9,1995$ Kobe earthquake, along with values for scenarios HAY 31 and HAY06 for the $M=7.25$ Hayward fault earthquake. Figure modified from Somerville (1995, Figure 10). 


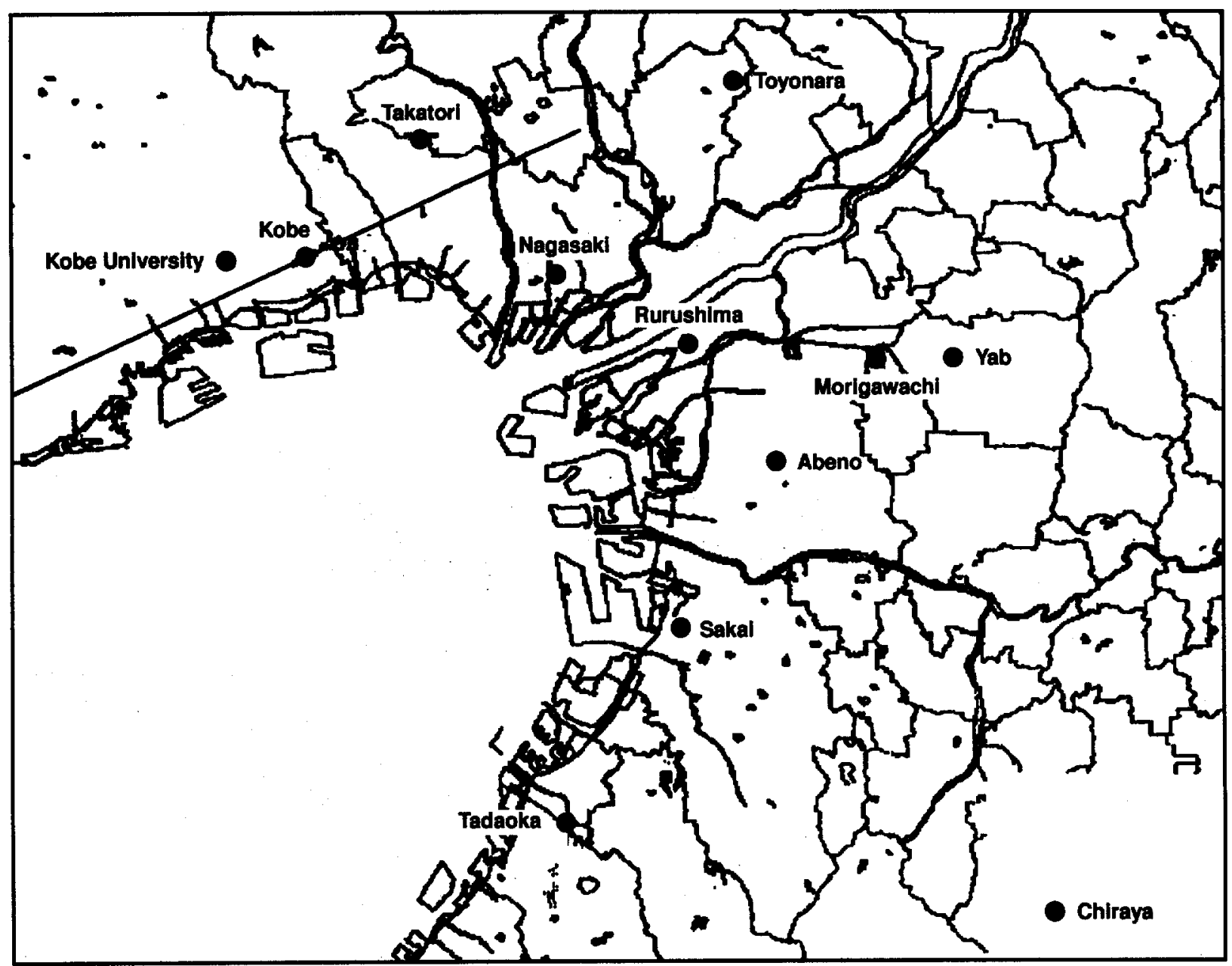

Figure 19. The location of two sites that recorded high acceleration response values. 


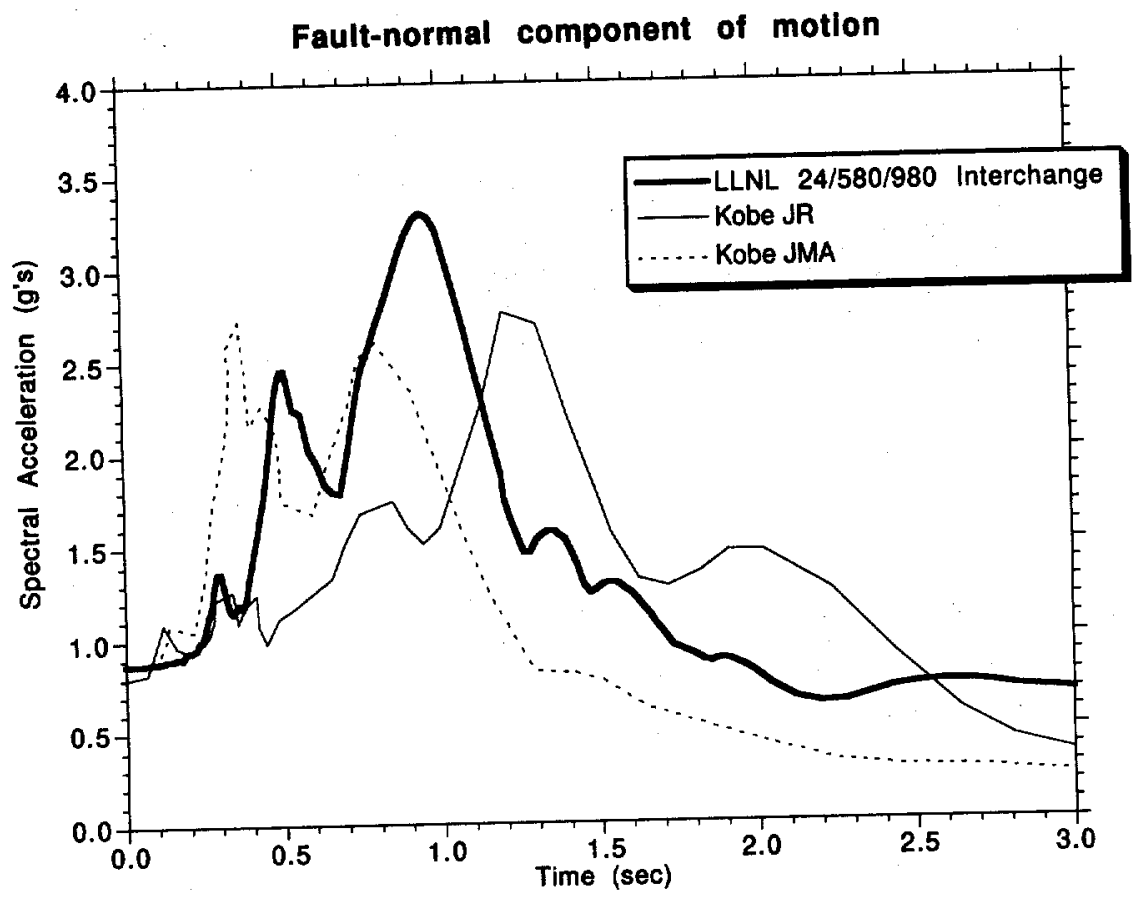

Figure 20. The results from scenarios HAY31.

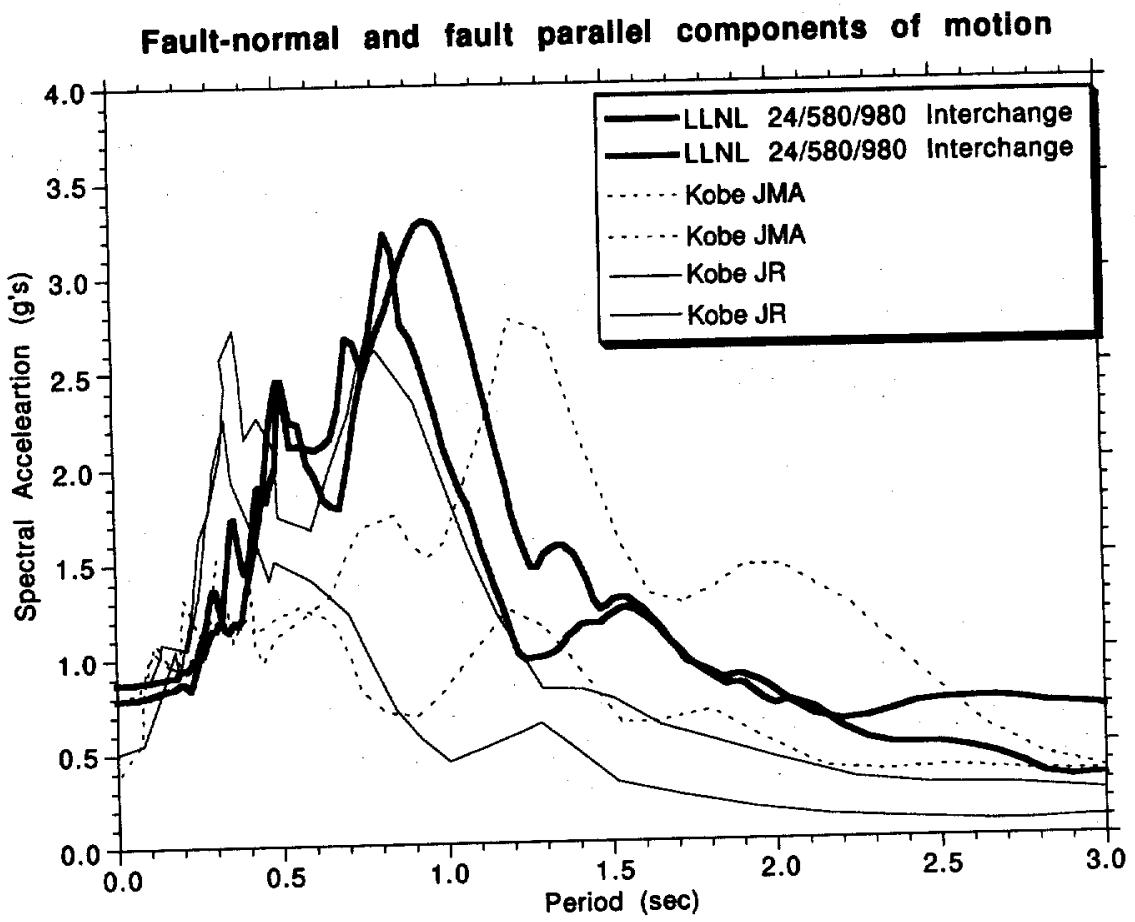

Figure 21. The results from scenarios HAY31. 
Table 1: List of rupture parameters used in this study.

\begin{tabular}{|c|c|c|c|c|c|c|c|c|}
\hline \multirow[b]{2}{*}{ Model } & \multirow[b]{2}{*}{ Asperities } & \multirow[b]{2}{*}{$\begin{array}{l}\text { Roughness } \\
(\%)\end{array}$} & \multirow[b]{2}{*}{$\begin{array}{l}\text { Moment (main, asperities) } \\
\times 10^{26} \text { dyne-cm }\end{array}$} & \multicolumn{3}{|c|}{ Hypocenter } & \multirow[b]{2}{*}{$\begin{array}{c}\text { Rupture } \\
\text { velocity (xVS) }\end{array}$} & \multirow[b]{2}{*}{$\begin{array}{c}\text { Healing } \\
\text { velocity (XVR) }\end{array}$} \\
\hline & & & & Latitude & Longitude & $\begin{array}{c}\text { Depth } \\
(\mathbf{k m})\end{array}$ & & \\
\hline HAY01 & none & 20 & 8.5 & 37.851 & 122.240 & 11.57 & 0.97 & 0.87 \\
\hline HAY02 & none & 10 & 8.5 & 38.038 & 122.402 & 12.51 & 0.98 & 0.93 \\
\hline HAY03 & $01,02,03,04$ & 10 & $7.91,0.12,0.09,0.15,0.24$ & 37.752 & 122.153 & 12.05 & 0.80 & 0.83 \\
\hline HAY04 & none & 10 & 8.5 & 37.832 & 122.223 & 12.72 & 0.93 & 0.82 \\
\hline HAY05 & none & 20 & 8.5 & 37.569 & 121.995 & 10.91 & 0.78 & 0.84 \\
\hline HAY06 & 01,02 & 33 & $8.16,0.08,0.26$ & 37.865 & 122.252 & 12.04 & 0.77 & 0.93 \\
\hline HAY07 & 01,02 & 10 & $8.34,0.09,0.08$ & 37.819 & 122.211 & 9.15 & 0.98 & 0.88 \\
\hline HAYOB & 01,02 & 0 & $7.51,0.50,0.49$ & $\mathbf{3 7 . 7 8 7}$ & 122.184 & 9.94 & 0.83 & 0.82 \\
\hline HAY09 & $01,02,03,04,05$ & 50 & $7.45,0.11,0.14,0.12,0.11,0.56$ & 37.598 & 122.020 & 11.59 & 0.88 & 0.93 \\
\hline HAY10 & $01,02,03,04,05$ & 10 & $7.70,0.22,0.13,0.21,0.19,0.05$ & 37.741 & 122.144 & 8.92 & 0.95 & 0.95 \\
\hline HAY11 & 01 & 25 & $7.79,0.71$ & 37.947 & 122.323 & 8.70 & 0.85 & 0.92 \\
\hline HAY12 & 01 & 50 & $8.07,0.43$ & 38.064 & 122.425 & 7.79 & 0.93 & 0.82 \\
\hline HAY13 & $01,02,03,04,05$ & 50 & $8.17,0.10,0.05,0.05,0.08,0.06$ & 37.601 & 122.022 & 12.77 & 0.98 & 0.89 \\
\hline HAY14 & 01 & 0 & $8.37,0.13$ & 37.727 & 122.132 & 12.48 & 0.91 & 0.95 \\
\hline HAY15 & 01,02 & 50 & $8.31,0.04,0.15$ & 37.726 & 122.131 & 11.82 & 0.92 & 0.84 \\
\hline HAY16 & none & 50 & 8.5 & 38.082 & 122.441 & 7.52 & 0.81 & 0.98 \\
\hline HAY17 & $01,02,03,04$ & 33 & $7.18,0.12,0.27,0.19,0.74$ & 37.970 & 122.343 & 12.19 & 0.81 & 0.90 \\
\hline HAY18 & $01,02,03$ & 10 & $7.81,0.23,0.39,0.07$ & 37.958 & 122.333 & 9.25 & 0.91 & 0.87 \\
\hline HAY19 & 01 & 20 & $8.45,0.05$ & 37.516 & 121.948 & 9.80 & 0.80 & 0.95 \\
\hline HAY2O & 01,02 & 10 & $7.56,0.54,0.40$ & 38.046 & 122.409 & 7.61 & 0.86 & 0.83 \\
\hline
\end{tabular}


Table 1: List of rupture parameters used in this study.

\begin{tabular}{|c|c|c|c|c|c|c|c|c|c|}
\hline & \multirow[b]{2}{*}{ Model } & \multirow[b]{2}{*}{ Asperlties } & \multirow[b]{2}{*}{$\begin{array}{l}\text { Roughness } \\
(\%)\end{array}$} & \multirow[b]{2}{*}{$\begin{array}{l}\text { Moment (main, asperities) } \\
\times 10^{26} \text { dyne-cm }\end{array}$} & \multicolumn{3}{|c|}{ Hypocenter } & \multirow[b]{2}{*}{$\begin{array}{c}\text { Rupture } \\
\text { velocity (xVS) }\end{array}$} & \multirow[b]{2}{*}{$\begin{array}{c}\text { Healing } \\
\text { velocity (XVR }\end{array}$} \\
\hline & & & & & Latitude & Longitude & $\begin{array}{l}\text { Depth } \\
\text { (km) }\end{array}$ & & \\
\hline & HAY21 & none & 50 & 8.5 & 38.049 & 122.412 & 8.36 & 0.93 & 0.83 \\
\hline & HAY22 & none & 25 & 8.5 & 37.947 & 122.323 & 8.69 & 0.82 & 0.88 \\
\hline & HAY23 & $01,02,03,04,05$ & $\mathbf{0}$ & $8.03,0.17,0.06,0.05,0.09,0.11$ & 37.896 & 122.278 & 7.79 & 0.83 & 0.97 \\
\hline & HAY24 & $01,02,03,04$ & 33 & $7.62,0.31,0.07,0.20,0.30$ & 37.951 & 122.326 & 11.00 & 0.77 & 0.85 \\
\hline & HAY25 & $01,02,03$ & 25 & $8.05,0.14,0.07,0.25$ & 37.704 & 122.112 & 11.87 & 0.97 & 0.91 \\
\hline & HAY26 & 01 & 50 & $8.41,0.09$ & 37.589 & 122.012 & 11.70 & 0.99 & 0.82 \\
\hline & HAY27 & $01,02,03$ & 20 & $8.04,0.07,0.22,0.17$ & 37.991 & 122.361 & 12.89 & 0.96 & 0.89 \\
\hline & HAY28 & $01,02,03$ & 50 & $7.67,0.48,0.22,0.13$ & $\mathbf{3 7 . 8 7 3}$ & 122.259 & 9.69 & 0.83 & 0.96 \\
\hline \multirow[t]{12}{*}{ w } & HAY29 & 01 & 10 & $7.90,0.60$ & 37.944 & 122.320 & 9.26 & 0.87 & 0.85 \\
\hline & HAY3O & 01 & 10 & $8.33,0.17$ & 37.767 & 122.167 & 9.99 & 0.79 & 0.92 \\
\hline & HAY31 & 01 & 20 & $8.44,0.06$ & 38.086 & 122.444 & 11.98 & 0.94 & 0.81 \\
\hline & HAY32 & $01,02,03,04$ & 20 & $8.02,0.18,0.05,0.16,0.08$ & 37.628 & 122.046 & 11.59 & 0.81 & 0.97 \\
\hline & HAY33 & $01,02,03,04,05$ & 10 & $7.83,0.33,0.05,0.06,0.10,0.13$ & 37.650 & 122.065 & 10.76 & 0.83 & 0.93 \\
\hline & HAY34 & none & 50 & 8.5 & 37.784 & 122.181 & 11.13 & 0.89 & 0.80 \\
\hline & HAY35 & 01,02 & 10 & $7.61,0.59,0.31$ & 38.001 & 122.370 & 9.44 & 0.83 & 0.93 \\
\hline & HAY36 & 01,02 & $\mathbf{0}$ & $8.28,0.17,0.05$ & 37.673 & 122.085 & 11.38 & 0.87 & 0.92 \\
\hline & HAY37 & $01,02,03$ & 50 & $8.15,0.09,0.19,0.07$ & 37.584 & 122.007 & 12.88 & 0.77 & 0.99 \\
\hline & HAY38 & none & 10 & 8.5 & 37.786 & 122.183 & 8.46 & 0.86 & 0.91 \\
\hline & HAY39 & 01,02 & 25 & $8.27,0.12,0.11$ & 37.967 & 122.341 & 10.96 & 0.92 & 0.87 \\
\hline & HAY40 & $01,02,03,04,05$ & 33 & $7.46,0.20,0.37,0.06,0.12,0.29$ & 37.674 & 122.086 & 11.39 & 0.99 & 0.84 \\
\hline
\end{tabular}


Table 1: List of rupture parameters used in this study.

\begin{tabular}{|c|c|c|c|c|c|c|c|c|}
\hline \multirow[b]{2}{*}{ Model } & \multirow[b]{2}{*}{ Asperities } & \multirow[b]{2}{*}{$\begin{array}{l}\text { Roughness } \\
\text { (\%) }\end{array}$} & \multirow[b]{2}{*}{$\begin{array}{l}\text { Moment (main, asperities) } \\
\times 10^{26} \text { dyne-cm }\end{array}$} & \multicolumn{3}{|c|}{ Hypocenter } & \multirow[b]{2}{*}{$\begin{array}{c}\text { Rupture } \\
\text { velocity (xVS) }\end{array}$} & \multirow[b]{2}{*}{$\begin{array}{c}\text { Healing } \\
\text { velocity (xVR) }\end{array}$} \\
\hline & & & & Latitude & Longitude & $\begin{array}{l}\text { Depth } \\
(\mathbf{k m})\end{array}$ & & \\
\hline HAY41 & 01 & 33 & $8.45,0.05$ & 37.861 & 122.248 & 12.39 & 0.86 & 0.99 \\
\hline HAY42 & $01,02,03,04$ & 10 & $8.15,0.06,0.11,0.13,0.06$ & 37.948 & 122.324 & 12.52 & 0.83 & 0.99 \\
\hline HAY43 & 01 & 20 & $8.06,0.44$ & 37.644 & 122.060 & 10.05 & 0.88 & 0.83 \\
\hline HAY44 & $01,02,03,04$ & 33 & $7.84,0.14,0.27,0.10,0.15$ & 37.900 & 122.282 & 11.78 & 0.96 & 0.96 \\
\hline HAY45 & $01,02,03,04$ & 33 & $7.98,0.18,0.05,0.09,0.20$ & 37.796 & 122.192 & 10.41 & 0.90 & 0.80 \\
\hline HAY46 & $01,02,03,04$ & 20 & $8.02,0.16,0.11,0.09,0.11$ & 37.908 & 122.289 & 7.75 & 0.75 & 0.98 \\
\hline HAY47 & $01,02,03,04,05$ & 20 & $7.27,0.10,0.44,0.25,0.17,0.26$ & 37.526 & 121.957 & 9.72 & 0.80 & 0.98 \\
\hline HAY48 & $01,02,03$ & 33 & $8.02,0.27,0.16,0.05$ & 37.907 & 122.288 & 9.89 & 0.80 & 0.93 \\
\hline HAY49 & none & 50 & 8.5 & 37.730 & 122.135 & 12.75 & 0.92 & 0.85 \\
\hline HAY50 & $01,02,03,04,05$ & $\mathbf{0}$ & $7.17,0.24,0.21,0.18,0.13,0.56$ & 37.737 & 122.141 & 8.04 & 0.94 & 0.80 \\
\hline HAY51 & $01,02,03,04$ & 50 & $7.34,0.25,0.27,0.54,0.11$ & 37.660 & 122.074 & 11.41 & 0.81 & 0.89 \\
\hline HAY52 & $01,02,03,04$ & 10 & $8.09,0.08,0.12,0.14,0.07$ & 38.010 & 122.378 & 12.64 & 0.94 & 0.80 \\
\hline HAY53 & $01,02,03,04,05$ & 25 & $6.85,0.09,0.12,0.10,0.78,0.57$ & 37.978 & 122.350 & 11.07 & 0.84 & 0.86 \\
\hline HAY54 & 01 & 10 & $8.21,0.29$ & 38.074 & 122.433 & 11.02 & 0.88 & 0.98 \\
\hline HAY55 & 01 & 10 & $8.41,0.09$ & 37.984 & 122.355 & 7.72 & 0.96 & 0.95 \\
\hline HAY56 & $01,02,03,04,05$ & 20 & $7.48,0.57,0.09,0.25,0.05,0.07$ & 38.046 & 122.409 & 7.84 & 0.82 & 0.86 \\
\hline HAY57 & 01,02 & 25 & $8.20,0.23,0.07$ & 38.086 & 122.444 & 9.90 & 0.81 & 0.82 \\
\hline HAY58 & $01,02,03$ & 33 & $7.88,0.45,0.09,0.08$ & 37.673 & 122.085 & 9.62 & 0.82 & 0.85 \\
\hline HAY59 & none & 33 & 8.5 & 37.932 & 122.310 & 9.95 & 0.81 & 0.94 \\
\hline HAY60 & $01,02,03,04$ & 33 & $7.99,0.17,0.20,0.09,0.05$ & 37.643 & 122.059 & 11.81 & 0.95 & 0.87 \\
\hline
\end{tabular}


Table 1: List of rupture parameters used in this study.

\begin{tabular}{|c|c|c|c|c|c|c|c|c|}
\hline \multirow[b]{2}{*}{ Model } & \multirow[b]{2}{*}{ Asperities } & \multirow[b]{2}{*}{$\begin{array}{l}\text { Roughness } \\
\text { (\%) }\end{array}$} & \multirow[b]{2}{*}{$\begin{array}{c}\text { Moment (main, asperities) } \\
\times 10^{26} \text { dyne-cm }\end{array}$} & \multicolumn{3}{|c|}{ Hypocenter } & \multirow[b]{2}{*}{$\begin{array}{c}\text { Rupture } \\
\text { velocity (xVS) }\end{array}$} & \multirow[b]{2}{*}{$\begin{array}{c}\text { Healing } \\
\text { velocity }(\mathrm{xVR})\end{array}$} \\
\hline & & & & Latltude & Longltude & $\begin{array}{l}\text { Depth } \\
\text { (km) }\end{array}$ & & \\
\hline HAY61 & $01,02,03,04$ & 20 & $7.50,0.12,0.48,0.09,0.30$ & 37.686 & 122.096 & 10.25 & 0.88 & 0.82 \\
\hline HAY62 & none & 33 & 8.5 & 38.034 & 122.398 & 12.44 & 0.94 & 0.88 \\
\hline HAY63 & 01 & 20 & $8.40,0.10$ & 37.705 & 122.113 & 11.88 & 0.95 & 0.88 \\
\hline HAY64 & 01,02 & 10 & $8.12,0.10,0.27$ & 37.966 & 122.340 & 12.26 & 0.81 & 0.85 \\
\hline HAY65 & none & 20 & 8.5 & 37.822 & 122.215 & 9.52 & 0.77 & 0.90 \\
\hline HAY66 & $01,02,03,04$ & 50 & $7.73,0.19,0.32,0.16,0.10$ & 37.630 & 122.048 & 12.96 & 0.92 & 0.97 \\
\hline HAY67 & $01,02,03,04,05$ & 20 & $7.84,0.07,0.32,0.06,0.05,0.16$ & 37.882 & 122.267 & 9.30 & 0.98 & 0.81 \\
\hline HAY68 & $01,02,03,04$ & 10 & $7.45,0.45,0.20,0.16,0.23$ & 37.624 & 122.042 & 8.95 & 0.76 & 0.99 \\
\hline HAY69 & 01,02 & 25 & $8.29,0.09,0.12$ & 37.555 & 121.982 & 12.61 & 0.95 & 0.92 \\
\hline HAY70 & 01 & 33 & $8.13,0.37$ & 37.698 & 122.107 & 9.21 & 0.93 & 0.87 \\
\hline HAY71 & 01,02 & o & $8.05,0.15,0.30$ & 37.997 & 122.366 & 11.49 & 0.97 & 0.85 \\
\hline HAY72 & none & 20 & 8.5 & 37.563 & 121.989 & 9.22 & 0.98 & 0.95 \\
\hline HAY73 & $01,02,03,04$ & 0 & $7.43,0.08,0.62,0.09,0.27$ & 37.861 & 122.248 & 9.77 & 0.85 & 0.83 \\
\hline HAY74 & $01,02,03,04$ & 0 & $7.75,0.11,0.13,0.15,0.36$ & 37.557 & 121.984 & 11.12 & 0.97 & 0.84 \\
\hline HAY75 & $01,02,03,04$ & 50 & $7.54,0.42,0.18,0.06,0.30$ & 37.921 & 122.30 & 10.51 & 0.96 & 0.83 \\
\hline HAY76 & $01,02,03,04$ & 33 & $7.35,0.49,0.22,0.23,0.22$ & 37.717 & 122.123 & 8.19 & 0.92 & 0.94 \\
\hline HAY77 & 01,02 & 0 & $8.23,0.14,0.13$ & 37.784 & 122.181 & 9.76 & 0.81 & 0.89 \\
\hline HAY78 & $01,02,03,04,05$ & 20 & $7.59,0.19,0.30,0.11,0.21,0.09$ & 37.611 & 122.031 & 10.78 & 0.85 & 0.98 \\
\hline HAY79 & $01,02,03$ & 33 & $8.14,0.19,0.09,0.08$ & 37.938 & 122.315 & 11.43 & 0.80 & 0.94 \\
\hline HAY80 & $01,02,03$ & 50 & $7.72,0.58,0.09,0.12$ & 37.750 & 122.151 & 8.56 & 0.96 & 0.88 \\
\hline
\end{tabular}


Table 1: List of rupture parameters used in this study.

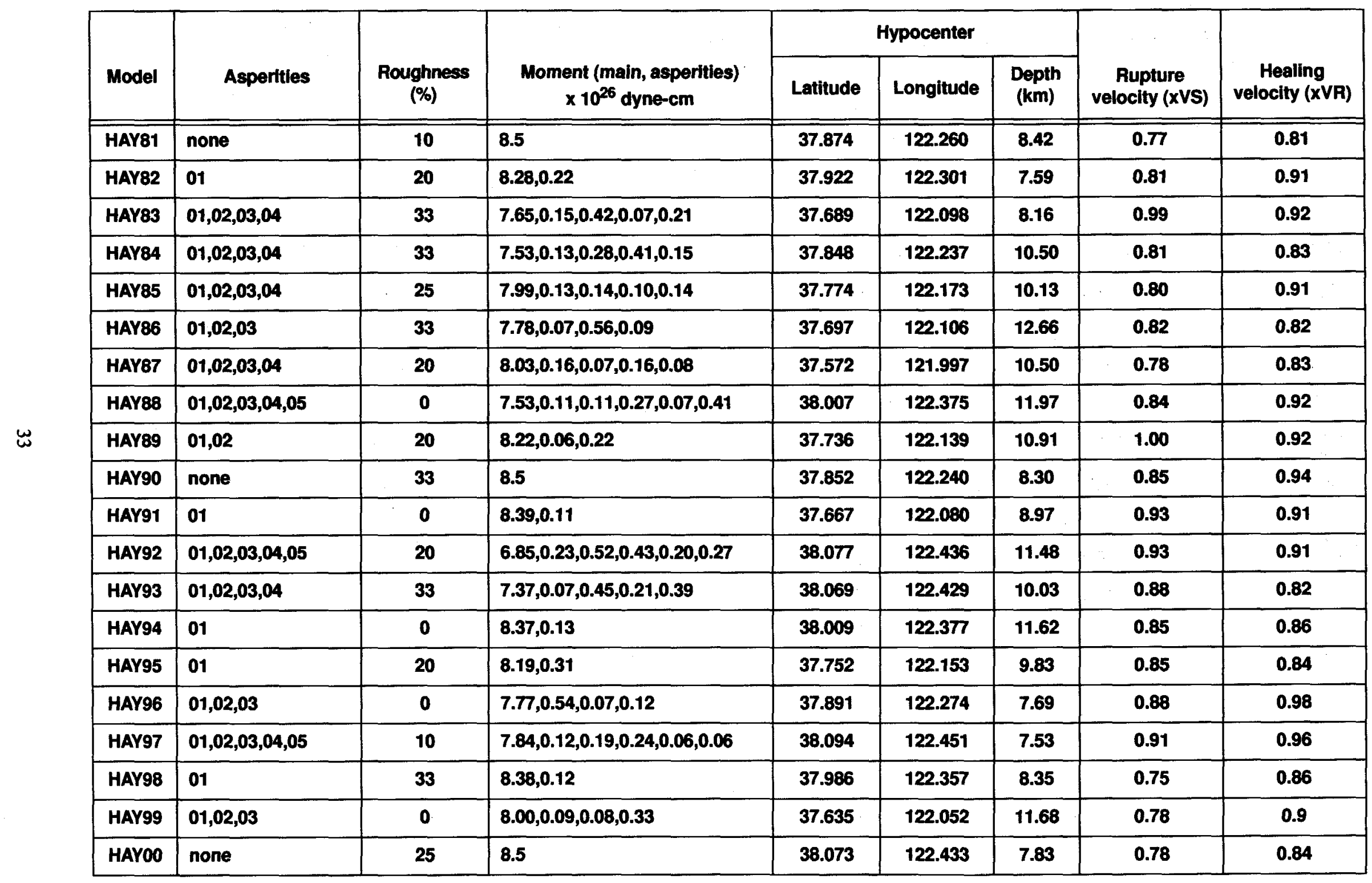


Table 2: Strong motion recordings less than $5 \mathrm{~km}$ from $M \geq 6.9$ earthquakes. Data from Somerville (1995).

\begin{tabular}{lcccccc}
\hline Earthquake & Magnitude & Site & Geology & Distance & $\begin{array}{c}\text { Peak } \\
\text { acceleration } \\
\text { (g) }\end{array}$ & $\begin{array}{c}\text { Peak } \\
\text { velocity } \\
\text { (cm/sec) }\end{array}$ \\
\hline Loma Prieta, 1989 & 7.0 & Corralitos & Soil & 4.3 & 0.51 & 43.9 \\
Loma Prieta, 1989 & 7.0 & Los Gatos & Rock & 3.5 & 0.66 & 105.5 \\
Landers, 1992 & 7.3 & Lucerne V. & Soil & 1.1 & 0.76 & 127.5 \\
Kobe, 1995 & 6.9 & Kobe Univ. & Rock & 3.8 & 0.33 & 49.1 \\
Kobe, 1995 & 6.9 & Kobe & Soil & 3.4 & 0.86 & 104.3 \\
Kobe, 1995 & 6.9 & Takatori & Soil & 4.3 & 0.81 & 174.9 \\
\hline
\end{tabular}

Table 3: Fault normal (FN) and fault parallel (FP) values of peak acceleration and velocity. Data from Somerville (1995).

\begin{tabular}{lcccccccc}
\hline & & & & \multicolumn{2}{c}{$\begin{array}{c}\text { Peak } \\
\text { acceleration }\end{array}$} & \multicolumn{2}{c}{ Peak velocity } \\
\cline { 6 - 9 } Earthquake & Magnitude & Site & Distance & FN & FP & FN & FP \\
\hline Landers, 1992 & 7.3 & Lucerne V. & 1.1 & 0.76 & 0.73 & 127.5 & 95.3 \\
Synthetic, mean HAY83 & 7.25 & BKS & 1.4 & 0.50 & 0.40 & 100.0 & 45.0 \\
Kobe, 1995 & 6.9 & Takatori & 4.3 & 0.81 & 0.42 & 174.9 & 62.7 \\
Synthetic, $+\sigma$, HAY31 & 7.25 & STK & 4.3 & 0.87 & 0.69 & 140.0 & 100.0 \\
\hline
\end{tabular}




\section{References}

Abrahamson, N. A., P. G. Somerville, and C. A. Cornell (1990). Uncertainty in Numerical Strong Motion Predictions, in Proc. 4th U.S. National Conf. Earthquake Engineering, Vol. 1 (Earthquake Engineering Research Institute, May 20-24, Palm Springs, California).

Aki, K., and P. G. Richards (1980). Quantitative seismology, Theory and Methods, Volumes I and II, W. H. Freeman and Company, San Francisco, CA.

Boatwright, J. (1988). The seismic radiation from composite models of faulting, Bul. Seis. Soc. Am. 78, 489-508.

Das and Kostrov (1989). An elliptical asperity in shear: fracture process and seismic radiation. Geophys. J. R. Astron. Soc. 80, 725-742.

Foxall, William, Lawrence Hutchings, and Paul Kasameyer (1996). Prediction of Strong Ground Motion based upon Physical Constraints on Fault Rupture Scenarios. accepted to Bul. Seis. Soc. Am.

Frankel, Arthur (1995). Simulating strong motion of large earthquakes using recordings of small earthquakes: the Loma Prieta main shock as a test case. Bul. Seis. Soc. Am. 85, 1144-1160.

Fuis, Gary S., and Walter D. Mooney (1990). Lithospheric structure and tectonics from seismic refraction and other data, in The San Andreas Fault System, California, Robert E. Wallace, ed. U. S. Geological Survey Prof. Paper 1515, 207.

Hanks, T. C., and H. Kanamori (1979). A moment magnitude scale. J. Geophys. Res. 84, 2348-2350.

Heaton, T. H. (1978). Generalized ray models of strong ground motion, Ph.D. thesis, California Institute of Technology, Pasadena, CA.

Heaton, T. H. (1982). The 1971 San Fernando earthquake: a double event? Bul. Seis. Soc. Am. 72, 2037-2062.

Hutchings, L. (1988). Modeling strong earthquake ground motion with an earthquake simulation program EMPSYN that utilizes empirical Green's functions, Lawrence Livermore National Laboratory, Livermore, CA, UCRL-ID-105890, p. 122.

Hutchings, L. (1991). "Prediction" of strong ground motion for the 1989 Loma Prieta earthquake using empirical Green's functions, Bul. Seis. Soc. Am. 81, 88-121.

Hutchings, L. (1994). Kinematic earthquake models and synthesized ground motion using empirical green's functions. Bul. Seis. Soc. Am. 84, 1028-1050. 
Hutchings, L. J., S. P Jarpe, P. W. Kasameyer, and W. Foxall (1996). synthetic strong ground motions for engineering design utilizing empirical Green's functions in the proceedings of the Fourth Caltrans Seismic Research Workshop, July 1996.

Hutchings, L., and F. Wu (1990). Empirical Green's functions from small earthquakes-A waveform study of locally recorded aftershocks of the San Fernando earthquake. J. Geophys. Res. 95, 1187-1214.

Hutchings, L., and S. Jarpe (1995). Ground motion variability at the Highways 14 and I-5 interchange in the northern San Fernando Valley. In press Bul Seis Soc Am.

Jarpe, S. P., L. J. Hutchings, T. F. Hauk, and A. F. Shakel (1989) Selected strong- and weakmotion data from the Loma Prieta earthquake sequence, Seism. Res. Lett. 60, 167176.

Jarpe, S. P., and P. W. Kasameyer (1996). Validation of a procedure for calculating broadband strong motion time histories with empirical Green's functions. Bul. Seis. Soc. Am 86, 1116-1129.

Kennett, B. L. N. (1983). Seismic Wave Propagation in Stratified Media, Cambridge University Press, Cambridge.

Kostrov, B. V., and S. Das (1988). Principles of earthquake source mechanics, in Cambridge Monographs on Mechanics and Applied Mathematics, Cambridge University Press, Cambridge.

Lienkaemper, J. J., G. Borchert, J. F. Wilmesher, and D. Meier (1989). Holocene slip rate along the Hayward fault, northern California. EOS, Transactions of the American Geophysical Union, 70(43), 1349.

McCallen, D. B., and L. J. Hutchings (1995), Ground motion estimation and nonlinear seismic analysis. LLNL, UCRL-JC-121667. in press, Proceedings: 12th Conference on Analysis and Computation of the American Society of Civil Engineers, Chicago, Illinois, 1986.

Schultz (1990). The Mechanics of Earthquake Faulting, Cambridge University Press, Cambridge.

Schwartz, D. P., and K. J. Coppersmith (1984). Fault behavior and characteristic earthquakes: examples from the Wasatch and San Andreas faults. J. Geophys. Res. 89, 5681-5698.

Sibson, R. H. (1982). Fault zone models, heat flow, and the depth distribution of earthquakes in the continental crust of the United States. Bull. Seism. Soc. Am. 72, 15116.

Sieh, K. (1984). Lateral offsets and revised dates of large prehistoric earthquakes at Pallet Creek, southern California. J. Geophys. Res. 89, 7641-7670. 
Somerville (1995) Strong motion records from the Kobe, Japan earthquake of January 17, 1995, and implications for seismic hazards in California; pp 69-82. in SMIP95 Seminar on Seismological and Engineering Implications of Recent Strong-Motion Data, San Francisco, California, May 16, 1995; sponsored by California Strong Motion Instrumentation Program, Division of Mines and Geology.

Steidl, Jamison H., Alexei G. Tumarkin, and Ralph J. Archuleta (1996). What is a reference site? Bul. Seis. Soc. Am. 83, 1733-1748.

Tse, S. T., and J. R. Rice (1986). Crustal earthquake instability in relation to the depth variation of frictional slip properties. J. Geophys. Res. 91, 9452-9472.

Tumarkin, A. G., R. J. Archuleta, and R. Madariaga (1994). Basic scaling relations for composite models. Bull. Seism. Soc. Am. 84(4).

Wald, David J., Hiroo Kanamori, Donald V. Helmberger, and Thomas Heaton (1993). Source study of the 1906 San Francisco Earthquake. Bul. Seis. Soc. Am. 83, 9811019.

Working Group on California Earthquake Probabilities (1990). Probabilities of Large Earthquakes in the San Francisco Bay Region, California. U.S. Geological Survey Circular 1053.

Working Group on California Earthquake Probabilities (1988). Probabilities of Large Earthquakes Occurring in California on the San Andreas Fault. U.S. Geological Survey Open-file Report 88-398. 


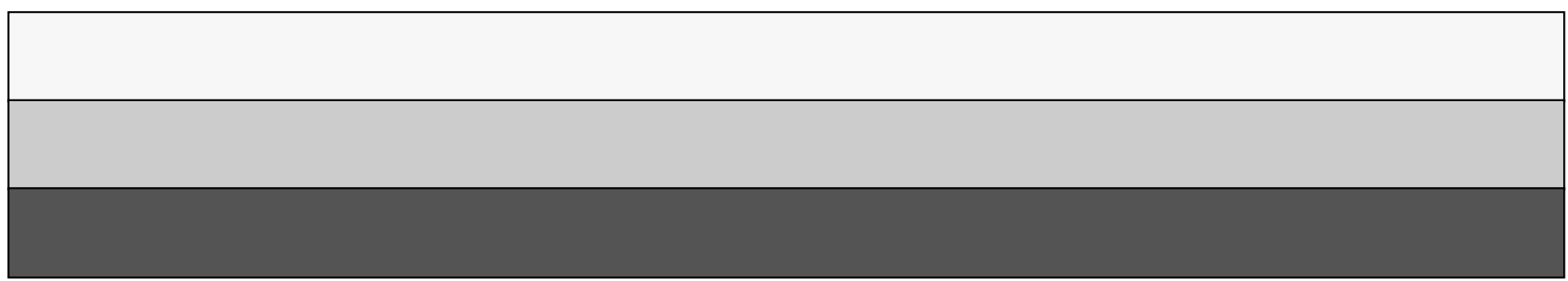

